\title{
Analysis and Planning Framework for Nuclear Plant Transformation
}

August 2020

U.S. Department of Energy

Office of Nuclear Energy 


\section{DISCLAIMER}

This information was prepared as an account of work sponsored by an agency of the U.S. Government. Neither the U.S. Government nor any agency thereof, nor any of their employees, makes any warranty, expressed or implied, or assumes any legal liability or responsibility for the accuracy, completeness, or usefulness, of any information, apparatus, product, or process disclosed, or represents that its use would not infringe privately owned rights. References herein to any specific commercial product, process, or service by trade name, trade mark, manufacturer, or otherwise, does not necessarily constitute or imply its endorsement, recommendation, or favoring by the U.S. Government or any agency thereof. The views and opinions of authors expressed herein do not necessarily state or reflect those of the U.S. Government or any agency thereof. 


\title{
Analysis and Planning Framework for Nuclear Plant Transformation
}

\author{
Ken Thomas, Jason Remer, Craig Primer \\ Idaho National Laboratory \\ Don Bosnic, Henry Butterworth, Charles Edwards, Gene Foote \\ Xcel Energy, Inc. \\ Asgeir Drøivoldsmo, Grete Rindahl, Robert McDonald \\ Institute for Energy Technology \\ Sean Lawrie, Ed Baker \\ ScottMadden, Inc.
}

\author{
August 2020 \\ Idaho National Laboratory \\ Idaho Falls, Idaho 83415 \\ http://www.inl.gov \\ Prepared for the \\ U.S. Department of Energy \\ Office of Nuclear Engineering \\ Under DOE Idaho Operations Office \\ Contract DE-AC07-05ID14517
}




\section{ABSTRACT}

Commercial nuclear power in the U.S. has been an unqualified success by any measure, providing safe, low-cost, carbon-free baseload electricity for decades. Today, the industry is at the peak of its historical performance in terms of generation output, reliable operations, and demonstrated nuclear safety. However, with the emergence of subsidized renewables and shale-gas generation, it is no longer among the lowest-cost electric generation sources. The business model that served the operating nuclear fleet so well over its initial lifespan is now a drag on cost performance, due to its reliance on a large, highly skilled labor force. In contrast, digital technology and innovation are enabling dramatic efficiencies in energy production, resulting in fierce competition for commodities such as electricity.

The nuclear power industry responded to this challenge with many initiatives to improve efficiency and modernize plant equipment, especially in areas where reliability and obsolescence issues are pressing. However, it would be a missed opportunity to merely modernize the plant components and work processes of an outdated business model formulated to manage the technology of the $1960 \mathrm{~s}$. Rather, the greater opportunity is to transform that business model into one that fully exploits the capabilities of modern digital technology, resulting in substantially lower production costs and sustainable market viability.

A successful example of one such transformation is the concept of integrated operations (IO), introduced into the North Sea oil and gas $(\mathrm{O} \& \mathrm{G})$ industry a couple decades ago when the profitability of operating these fields was severely threatened by low global petroleum prices and the high overhead of operating offshore O\&G platforms. This effort resulted in significant changes to how these oil fields were operated, enabling the industry to continue operating the platforms profitably. This example has remarkable parallels to the U.S. commercial nuclear industry.

This report provides an analysis and planning framework for transforming the current nuclear power plant (NPP) operating model via transferable learnings from the North Sea O\&G industry. This framework is termed "Integrated Operations for Nuclear" (ION). This report describes the key principles and methods of IO and how they are being applied via collaboration between the Department of Energy (DOE) Light Water Reactor Sustainability (LWRS) Program and Xcel Energy in an initiative to transform the NPP operating model in order to foster performance improvement and long-term sustainability. It describes a method for bringing the operating costs of a nuclear fleet in line with market-based pricing and transforming work functions to reduce costs via technological innovations.

This initiative will continue over the next several years in the form of detailed development of transformative concepts for NPPs - the results of which will be published as a follow-up to this initial report on ION. 


\section{CONTENTS}

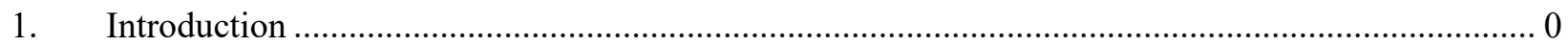

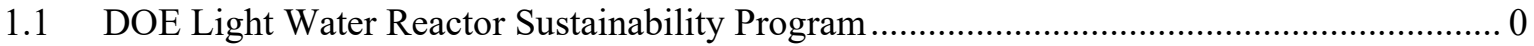

1.2 Advanced Concept of Operations Project ...................................................................... 1

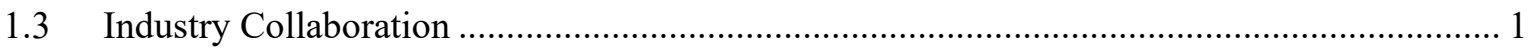

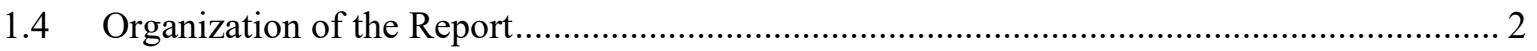

2. The Case for Nuclear Plant Transformation................................................................................ 2

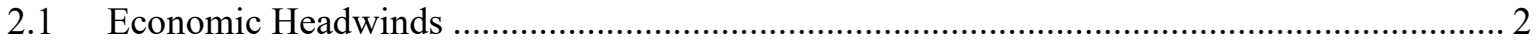

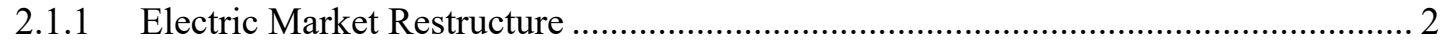

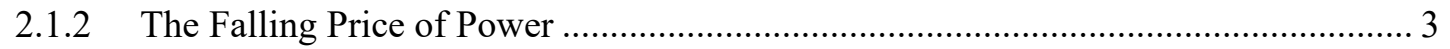

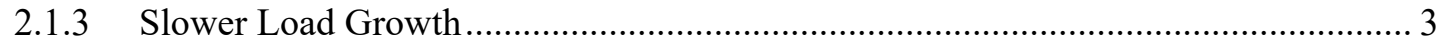

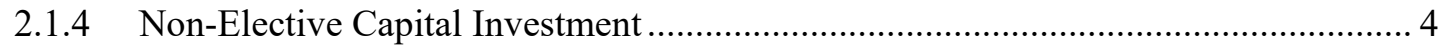

2.2 Diminishing Returns of the Current Business Model ..................................................... 4

2.2.1 The Lifecycle of an Operational Paradigm (S-Curve) ................................................ 4

2.2.2 Recognizing the Limits of an Operational Paradigm ............................................... 5

2.2.3 Particular Concerns of the Current Operational Paradigm.......................................... 6

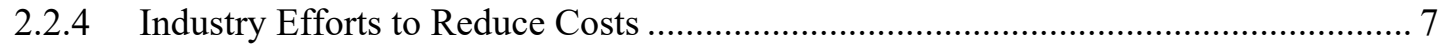

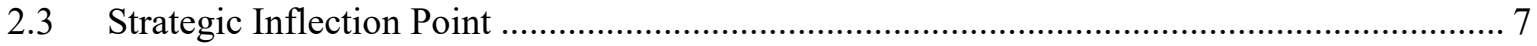

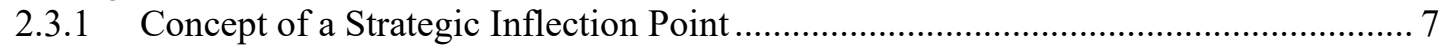

2.3.2 Strategic Inflection Point for the U.S. Nuclear Fleet .............................................. 9

2.4 The Need for a Transformed Business Model ................................................................. 10

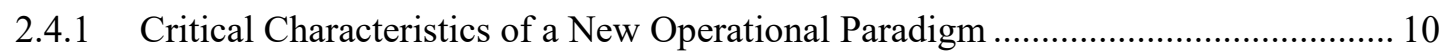

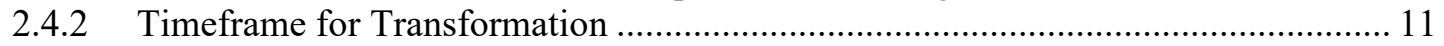

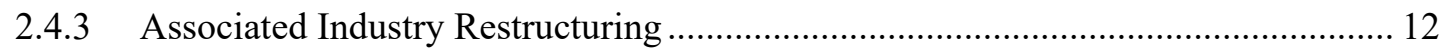

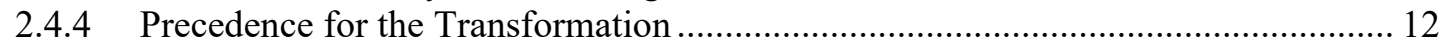

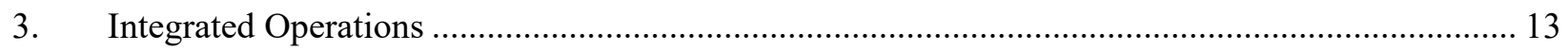

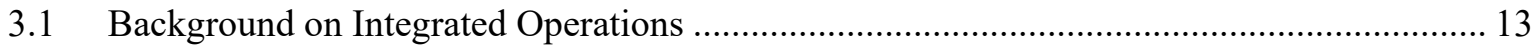

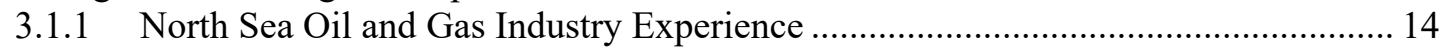

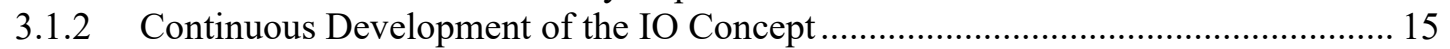

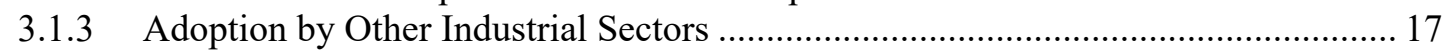

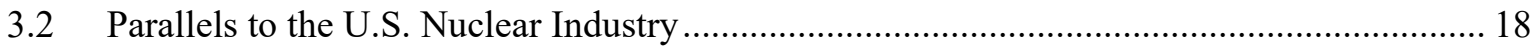

3.2.1 Continuous Operation Production Facilities …....................................................... 19

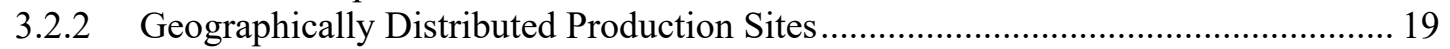

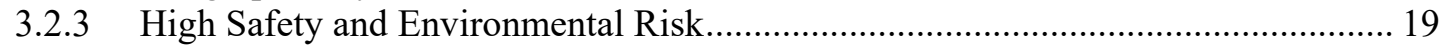

3.2.4 High Level of Technical Expertise and Technology Required .................................. 20

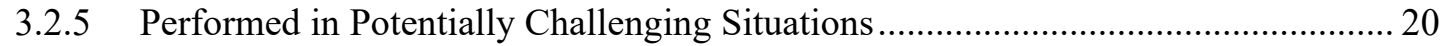

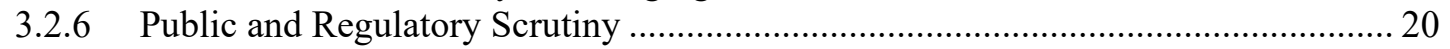

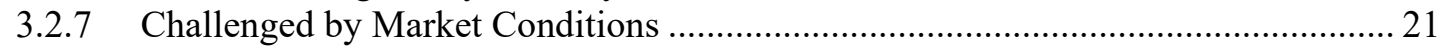

3.3 Integrated Operations Key Operational Concepts........................................................ 21

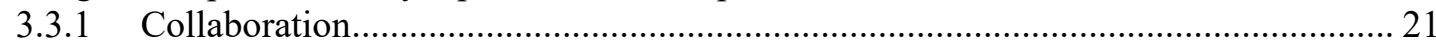

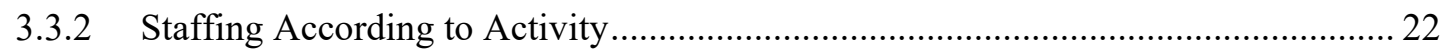

3.3.3 Campaign-Based (Block) Maintenance and Modifications ...................................... 22

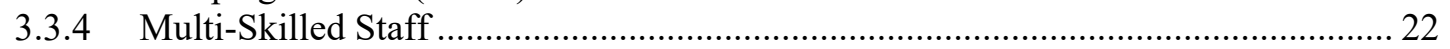




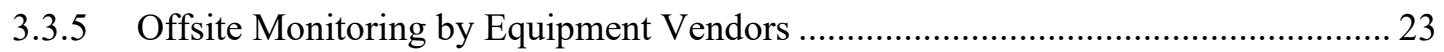

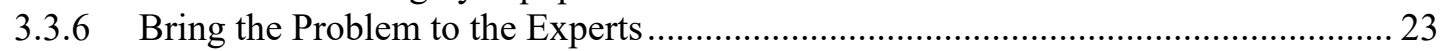

3.3.7 Collaboration between Operators and Contractors .............................................. 24

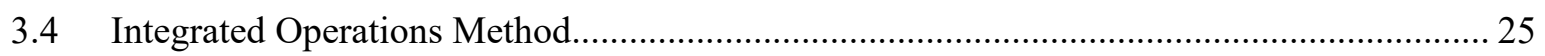

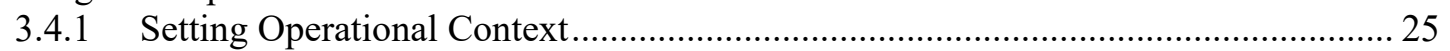

3.4.2 Identifying Key Capabilities ................................................................. 25

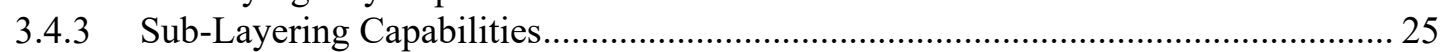

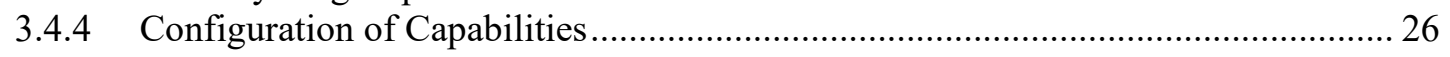

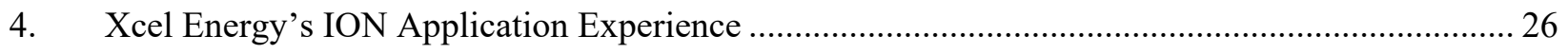

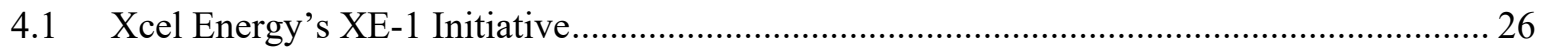

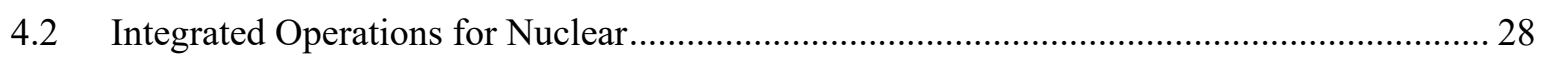

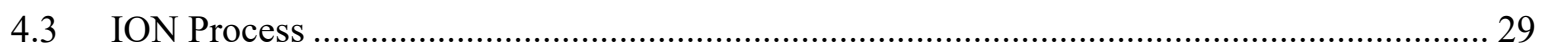

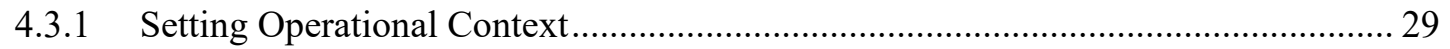

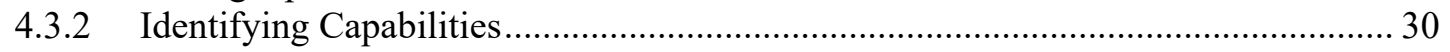

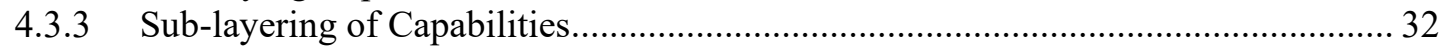

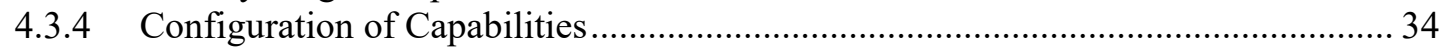

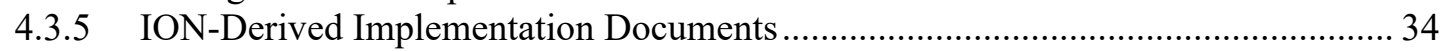

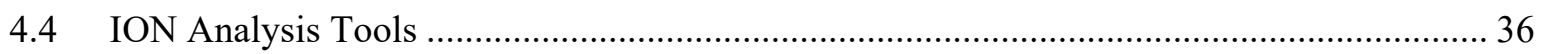

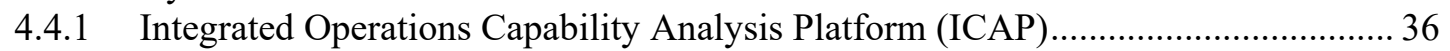

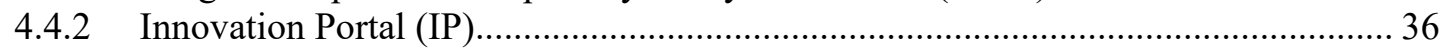

4.4.3 EPRI Business Case Analysis Method (BCAM) Interface …................................. 36

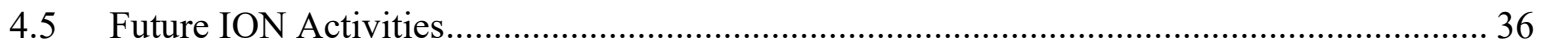

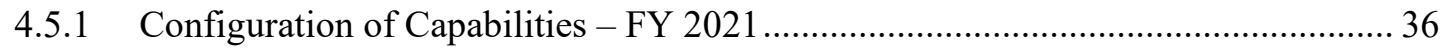

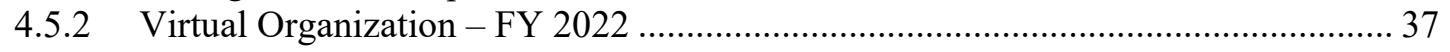

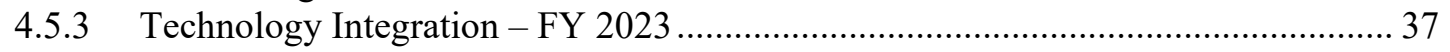

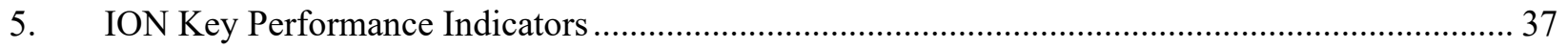

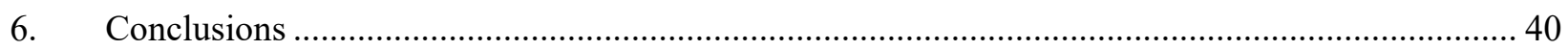

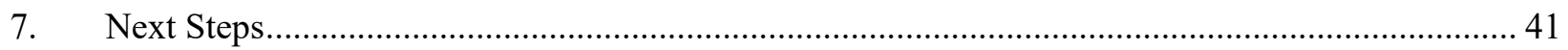

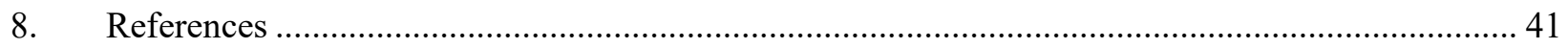

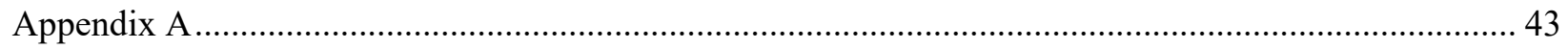

FIGURES

Figure 1. Performance based on the current operating model. ........................................................... 5

Figure 2. Performance improvement based on a digital transformation of the NPP operating

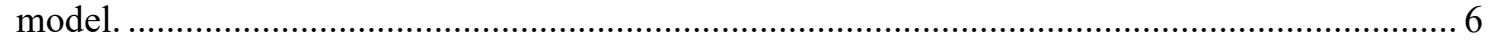

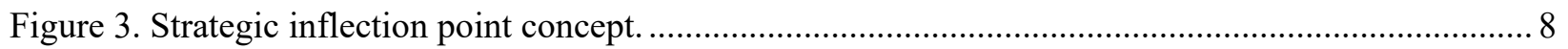

Figure 4. Concept sketch showing real-time data and communication as a basis of onshore support for offshore production and drilling installations. 14 
Figure 5. OLF prediction for the two steps in IO implementation...................................................... 16

Figure 6. (Left) Xcel Energy's Prairie Island Nuclear Generating Station, Minnesota. (Right) Wintershall Brage oil production platform, Norwegian Continental Shelf.

Figure 7. Illustration of a typical U.S. nuclear plant control room (left) and a modern petroleum control room (right).

Figure 8. General development and digitalization change how work is performed.

Figure 9. The basic principle behind IO. (Left) An illustration of self-supported fields. (Right) Shared expertise across fields. HRM, SS, etc., are different functional areas.

Figure 10. A capability is the synthesis of interdependent resources involving people, processes, technology, and governance - all enabling the direct creation of added value.

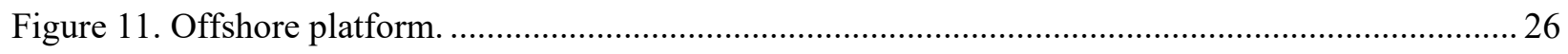

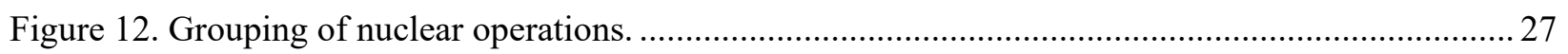

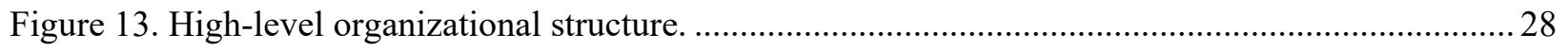

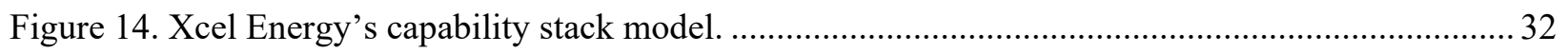

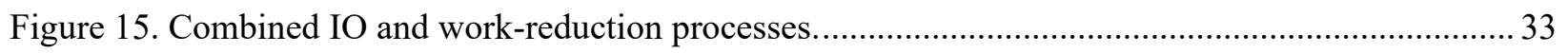

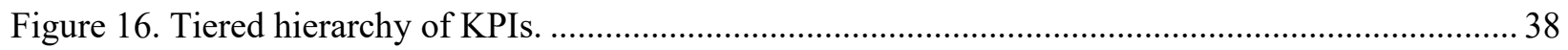

\section{TABLES}

Table 1. Tiered KPI chart. 


\section{ACRONYMS}

$\begin{array}{ll}\text { BCMW } & \text { Business Case Methodology Workbook } \\ \text { DOE } & \text { Department of Energy } \\ \text { IFE } & \text { Institute for Energy Technology } \\ \text { IO } & \text { Integrated Operations } \\ \text { ION } & \text { Integrated Operations for Nuclear } \\ \text { KPI } & \text { Key Performance Indicators } \\ \text { INPO } & \text { Institute of Nuclear Power Operations } \\ \text { LWRS } & \text { Light Water Reactor Sustainability } \\ \text { NCS } & \text { Norwegian Conventional Shelf } \\ \text { NEI } & \text { Nuclear Energy Institute } \\ \text { NPP } & \text { Nuclear Power Plant } \\ \text { NPV } & \text { Net Present Value } \\ \text { NRC } & \text { Nuclear Regulatory Commission } \\ \text { O\&G } & \text { Oil and Gas } \\ \text { O\&M } & \text { Operations and Maintenance } \\ \text { OLF } & \text { Norwegian Oil Industry Association } \\ \text { PTPG } & \text { Process, Technology, People, and Governance }\end{array}$




\section{Analysis and Planning Framework for Nuclear Plant Transformation}

\section{Introduction}

Commercial nuclear power in the U.S. has been an unqualified success by any measure, having provided safe, low-cost, carbon-free baseload electricity for decades. Today, the industry is at the peak of its historical performance in terms of generation output, reliable operations, and demonstrated nuclear safety. However, with the emergence of subsidized renewables and shale-gas generation, it is no longer among the lowest-cost electric generation sources. The business model that served the operating nuclear fleet so well over its initial lifespan is now a drag on cost performance, due to its reliance on a large, highly skilled labor force. In contrast, digital technology and innovation are enabling dramatic efficiencies in production, resulting in fierce competition for commodities such as electricity.

The nuclear power industry responded to this challenge with many initiatives to improve efficiency and modernize plant equipment, especially in areas where reliability and obsolescence issues are pressing. However, it would be a missed opportunity to merely modernize the plant components and work processes of an outdated business model formulated to manage the technology of the 1960s. Rather, the greater opportunity is to transform that business model into one that fully exploits the capabilities of modern digital technology, resulting in substantially lower production costs and sustainable market viability. This report provides an analysis and planning framework to foster such a transformation.

\subsection{DOE Light Water Reactor Sustainability Program}

The Light Water Reactor Sustainability (LWRS) Program is sponsored by the U.S. Department of Energy (DOE) and coordinated through a variety of mechanisms and interactions with industry, vendors, suppliers, regulatory agencies, and other industry R\&D organizations. It conducts research to develop technologies and other solutions for improving plant economics, reliability, and safety, in addition to extending the operations of the national fleet of nuclear power plants (NPPs) [1].

The LWRS Program has two objectives in maintaining the long-term operations of the existing fleet:

1. To provide scientific, technology-based solutions to help industry overcome the current labor-intensive business model and associated practices

2. To manage the aging of systems, structures, and components so NPPs can continue to operate safely and cost-effectively.

The DOE LWRS Program's Plant Modernization Pathway conducts a broad R\&D program to address the technical and economic sustainability needs of the operating U.S nuclear fleet. This R\&D program is targeted to ensure that U.S. NPPs are well-positioned for many additional years of operation in support of national energy and environmental security goals [2]. The pathway conducts this research in collaboration with nuclear industry partners who share this sustainability objective. This includes nuclear utilities, industry support groups, suppliers, other research organizations, universities, and consultants/contractors.

Since the inception of the LWRS Program, the Plant Modernization Pathway has conducted research activities over a broad range of NPP functional areas, addressing critical issues of technology obsolescence, plant reliability, plant worker efficiency, and operations and maintenance (O\&M) cost reduction [3]. Development and demonstration of these technologies and related methodologies have been conducted with collaborating partners, including nuclear utilities, nuclear industry suppliers, and other research organizations. The result is a set of proven technologies that, taken together, address the requirements for achieving the much-needed modernization of legacy plant systems (as well as related operation and support processes) to ensure long-term sustainability and economic viability. To this end, a research project entitled "Advanced Concept of Operations" is being sponsored by the 
Pathway to provide a means of NPP business model transformation, as described in the following section.

\subsection{Advanced Concept of Operations Project}

The overall objective of the Advanced Concept of Operations project is to provide the nuclear industry with a validated means of bringing operating costs in line with the realities of the electric market. This involves transforming their operating model - a transformation accomplished through business-driven technology innovation - to address the two major barriers to extended plant life: technical and economic viability over the long term. The project focuses on developing a businessdriven approach for transforming the operating model of commercial NPPs from labor-centric to technology-centric, as many other industrial sectors have done to survive in today's marketplace.

The underlying concept of this operating-model transformation is known as "integrated operations" (IO). IO is a system for integrating people, disciplines, organizations, and work processes by using cutting-edge information and communications technology to foster smarter decision-making. Over the past two decades, North Sea oil and gas $(\mathrm{O} \& \mathrm{G})$ companies implemented IO when restructuring their operating models to remain profitable amid declining offshore petroleum fields and depressed O\&G prices. Using advanced digital technologies, they moved operation and support functions onshore to serve multiple platforms. This is but one example of this type of business-model transformation.

In applying IO principles and methods to the nuclear power industry, the resulting planning and analysis framework was termed "integrated operations for nuclear" (ION) and serves as a businessdriven approach for transforming the operating model of commercial NPPs from labor-centric to technology-centric.

In addition, a set of computer-based applications used throughout the framework processes will be delivered to industry for analyzing this ION.

\subsection{Industry Collaboration}

This project is being conducted in collaboration with Xcel Energy Inc. A large utility serving the central U.S [4]. Xcel has announced goals of providing 100\% clean, carbon-free electricity by 2050 , with an $80 \%$ carbon reduction by 2035 , making them the first major U.S. utility to announce this level of carbon reduction [5].

To ensure that its nuclear operations remain competitive in future electric markets, Xcel Energy initiated the XE1 program to analyze nuclear-generation work functions in order to derive more efficient means of accomplishing their required outcomes through work elimination, requirement reduction, process improvement, technology application, and other forms of innovation. Through this collaboration, LWRS researchers are developing a framework and accompanying tool set for analyzing and formulating the transformed operating model that Xcel Energy will implement for maintaining excellent nuclear performance in a cost-competitive manner.

Norway's Institute for Energy Technology (IFE), sponsor of the Halden Reactor Project, has helped lead the development of IO principles and methods, as well as foster technologies that enable this transformation. As part of the project team, they are contracted to apply their IO knowledge to the NPP operating model. This past fall, they provided a new report to the LWRS Program, along with lessons learned from petroleum industry IO, based on their deep understanding of both offshore petroleum production and NPP operations/support.

ScottMadden Management Consultants is also part of the project team, providing cost-benefit analyses and innovative concepts, both from the nuclear industry and other sectors. ScottMadden is also providing innovative concepts in key performance indicators and the effective application of measures to drive desired business performance.

In addition, Jason Remer (Remer Engineering) is part of the project team, offering NPP operational experience and Nuclear Energy Institute (NEI) regulatory initiative experience, digital instrumentation and controls, license extension, and associated plant aging management to the project. 


\subsection{Organization of the Report}

This report is organized into the following major sections detailing the motivation behind the project, the reasons for the current state of the U.S. nuclear power industry, the fundamental principles of IO, and the methods and results of this project to date:

Section 1

Background

Section 2

The Case for Nuclear

Plant Transformation

Section 3
Integrated Operations

Section 4

Xcel Energy ION

Application

Experience

Section 5

Key Performance

Indicators

Section 6

Summary

Section 7

Next Steps
Overall objectives of the project, DOE sponsorship, project approach, and project collaborators

Factors affecting the U.S. nuclear power industry, initiatives the industry has undertaken to address these factors, the concept of a strategic inflection point facing the industry, and the case for IO to ensure market competitiveness and long-term sustainability

A high-level presentation on the major principles and methods behind IO, its origins in the North Sea O\&G industry, and that industry's parallels to the U.S nuclear power industry

Overview of the ION methodology, its application in the Xcel Energy initiative, the results to date, use of ION tools, and future steps for full development

An approach to key performance indicators, other performance measures, and process diagnostic measures to ensure that enterprise business objectives are achieved and the maximum value of the IO method is realized

Key project results, lessons learned in implementing the methodology, and transferable learnings for the U.S. nuclear power industry

Planned research collaborations in Xcel Energy's application of the ION methodology, and planned activities to transfer the ION methodology/tools to the U.S. nuclear power industry

\section{The Case for Nuclear Plant Transformation}

The case for NPP transformation is driven by economic realities combined with new technological capabilities for transitioning the business model into something technically and economically sustainable. Digitization of the current NPP business model will only institutionalize the inefficiencies of the largely manual, paper-based work processes currently employed. Only through transformation will the full power of the new technologies be unleashed to achieve a nucleargeneration cost basis that is both competitive and enduring.

\subsection{Economic Headwinds}

Numerous factors came together over the past decade or so to challenge the economic viability of the U.S. operating nuclear fleet. Whereas it was once believed that component aging would be the major life-limiting factor of operating plants, the ability to compete in a diverse energy market has become the more imminent threat. In addition to plant shutdowns due to cost-prohibitive component repair, the industry has now experienced NPP shutdowns for purely economic reasons [6]. The following sections describe factors that account for this distressed nuclear power market.

\subsubsection{Electric Market Restructure}

Beginning in the 1990s, changes implemented in the electric market had huge implications for nuclear operations. Regulated, vertically integrated electric utilities began to be restructured into new forms of operating companies. Some markets were deregulated and converted over to various forms of open competition among generating sources. In many cases, these utilities were forced to divest 
their transmission systems to regional transmission operating companies obligated to neutrality in regard to generation and power wheeling. The result was that electric utilities could no longer favor and dispatch their own nuclear units but had to engage in price competition on a generating unit basis. Moreover, in some cases, this extended to competing on an hourly basis, as the price of electricity varied on time of day and the availability of renewable generation, pushing the nuclear units "underwater" at times when their total cost of production was less than the market price.

One strategy to help nuclear units cope with this came in the form of load following. However, this strategy has several disadvantages.

1. Revenue over a given time period obviously decreases when the plant operates below its design capacity. Moreover, the fact that nuclear generation is dominated by fixed rather than variable costs has a particularly negative effect on production costs $(\$ / \mathrm{MWh})$.

2. NPP designs are optimized for $100 \%$ power operations, and plant efficiency falls off at lower power levels, lowering the return on fuel investment.

3. Certain nuclear reactor transients occur during power changes, complicating nuclear operations and increasing both component and human performance challenges.

It should be noted that there may be some benefits here in the form of "hybrid generation," the ability to produce valuable products such as hydrogen via the NPP's electric and heat output when electric market prices are unfavorable. Moreover, these types of capabilities are switchable at the same rate (daily) that prices vary, allowing nuclear units to maintain reactor power at $100 \%$ while avoiding operating at a loss, thus preventing the negative effects of reactor power changes.

With the hybrid generation option still some time off, NPPs are stressed by current electric market realities in terms of generated revenue - just when investment is needed to improve plant economics and reduce generation costs. It is very difficult to make efficiency investments when revenues do not cover expenses.

\subsubsection{The Falling Price of Power}

The price of power has been substantially impacted over the past 15 years by the introduction of both shale-gas generation and renewable generation - primarily wind and solar. [7]

The discovery of new gas fields, along with hydraulic fracturing gas-recovery methods, led to historically low gas prices, with proven reserves lasting for the indefinite future. At one time, gas turbine generation was the most expensive form of generation and could only be used for peaking units. Now it can run as baseload and directly compete with nuclear's role in the generation mix. On the other hand, coal-based generation is rapidly being phased out due to larger air quality and waste issues, creating some headroom for nuclear power. The one threat to gas generation, despite generating only half as much carbon as coal, is the emerging state and utility goals to be carbon neutral by 2050 or so.

The generation costs of renewables have decreased in two ways. Costs and economies of scale have fallen as market size increased. Secondly, substantial government subsidies have been offered in the form of investment and production credits for renewables. The latter has a particularly onerous effect on the electric market, with some classes of wind generators earning up to \$24/MWh. [8] This means they can bid into the market even at a negative price and still make money. The effect on baseload nuclear generation is obvious in terms of market competition.

\subsubsection{Slower Load Growth}

Further exasperating the situation, electric load growth has slowed over the past decade or so. A higher growth rate would obviously create more market headroom for nuclear power.

One factor pertaining to this is energy efficiency. In the past, a substantial portion of a typical utility load was lighting. New energy-efficient lighting technologies such as compact fluorescents and LED lights significantly decreased this percentage. Similarly, more efficient appliances, heating and cooling units, better insulation, and industrial components such as motors also curtailed load growth. 
A second factor is economic changes, such as recessions and shifts from heavy industries to service-oriented businesses. Indeed, electric prices have been a factor in businesses relocating to areas with more favorable electricity prices. This was seen in some of the most intensive electric-based industries (i.e. large server farms for internet services). These types of changes have had a disproportionate effect on certain utilities.

One possible benefit of load growth is the growing prospect for electrification of economic industrial and transportation sectors as part of the recent decarbonization movement. Penetration of electric vehicles into the automobile industry is somewhat growing. Apart from any economic advantages (of which there are some), electric growth stands to benefit from societal choices regarding the phasing out of carbon-based energy over climate concerns.

\subsubsection{Non-Elective Capital Investment}

Over the past couple decades, the nuclear power industry has dealt with wave after wave of nondiscretionary capital investment to address safety and regulatory issues. This resulted in deferring needed reinvestment in the plants to address aging plant systems and was a missed opportunity to modernize NPPs through advanced digital technologies commonplace in other safety-critical industries.

The most recent instance of this was the significant modifications made in response to the Fukushima nuclear accident. Prior to that, there was a long parade of issues such as security response capabilities reactor containment building sump-screen clogging, reactor head weld concerns, degraded steam generators, and other nuclear safety improvements. When many industries reinvested in their plants via digital technologies to improve operating efficiencies, the available capital — dollar and human - was swallowed up by these issues. Thus, the industry found itself in the mid-2000s with a 1960s technology base.

Now, with available discretionary capital greatly reduced due to depressed energy prices, nuclear utilities need to both upgrade their aging plant systems and lower operating costs by investing in transformative business improvements such as centralized plant monitoring. However, because these transformative projects entail a degree of technical and financial risk, they are given lower priority than demands for reinvestment in plant infrastructure.

\subsection{Diminishing Returns of the Current Business Model}

Business models are formulated to address an enterprise's needs with respect to current requirements for production and competition, as well as external constraints such as regulation. They are generally somewhat flexible and adaptable to changing conditions and market forces. However, over time, the limitations of any given business model become more apparent as the rate and ease of business improvements decline due to new forces/factors in the business environment. The next section describes the typical lifecycle of a business model and how it has manifested in the NPP operational paradigm.

\subsubsection{The Lifecycle of an Operational Paradigm (S-Curve)}

Today, nuclear generation is a vital component of the nation's energy supply, providing safe, reliable, carbon-free electricity at relatively low cost. This is largely due to the impressive performance improvements achieved by industry over the past 15 years or so. In the mid-1990s, there was accelerated standardization of plant processes and the conducting of operations. This was due to the concerted efforts of the utilities and the Institute of Nuclear Power Operations (INPO) in setting challenging performance targets and undergirding these efforts with comprehensive process templates and human performance expectations.

As a result, performance improvements are evident in virtually every aspect of plant operations most notably in the capacity factor, scram rate, forced loss rate, dose, refueling outage length, and overall cost performance. All this was achieved while substantially improving nuclear safety performance. 
This also resulted in a fairly standard operating model for the U.S. light-water reactor fleet, based on these process and human performance standards. Operating experience and lessons learned were effectively incorporated throughout the industry; today, there is considerable uniformity from one nuclear utility to the next in regard to conducting nuclear operations and support activities.

However, sustaining these performance improvements is an ongoing concern. Every means or methodology of accomplishing an end is subject to the classic S-curve relationship between effort and performance, as illustrated in Figure 1 [9]. This has certainly proven true with respect to performance improvements in the light-water reactor fleet based on the current operating model.

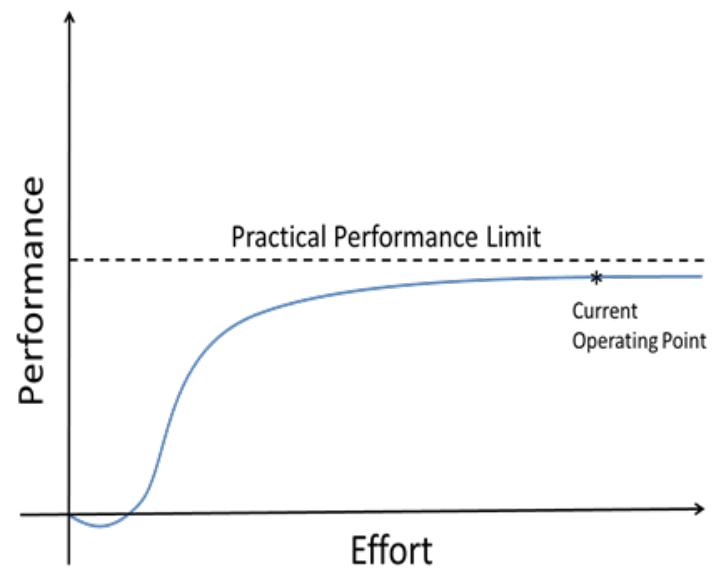

Figure 1. Performance based on the current operating model.

In the early years of the operating model, the industry was below the knee of the curve and enjoyed highly leveraged returns relative to effort. This roughly corresponded to the time period between the mid-1990s and mid-2000s. Below the knee of the curve, a given amount of effort results in an appreciable improvement in performance. As the operating model matured, much of the "lowhanging fruit" was exhausted, and the rate of improvement became impossible to maintain.

Beyond the knee of the curve, similar levels of effort result in only modest gains in performance, with ever-diminishing returns on what a given business model can deliver. Again, this has been evident in industry performance ever since the mid-2000s, with the rate of improvement greatly slowing - or even flattening - as is evident in the improved fleet capacity factors, scram rates, and forced loss rates.

\subsubsection{Recognizing the Limits of an Operational Paradigm}

As further indication, it is generally acknowledged by nuclear utility staff that more and more complexity has been added to plant processes, with only small increments of improved performance to show for it. This confirms that the industry's operating model is well out on the flat part of the curve and has been substantially exhausted of its performance improvement potential. If so, the industry requires a new operating model to provide an expanded basis for further performance improvements.

A new operating model would shift from a labor-centric basis to a technology-centric one. Digital technology is the foremost enabler of such a shift, potentially transforming virtually every aspect of NPP operations and support by combining the unexploited capabilities of digital I\&C systems with emerging technologies for enhancing human effectiveness, thereby creating a new paradigm for the plant operating model.

Such a development would draw a new performance curve and move the operating point back below the knee of the curve, once again enabling highly leveraged performance improvements at a reasonable effort, as illustrated in Figure 2. [9] 


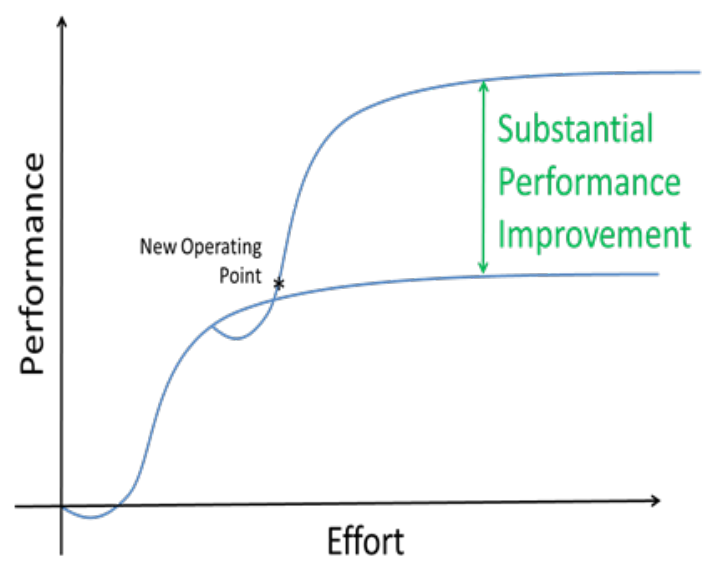

Figure 2. Performance improvement based on a digital transformation of the NPP operating model.

\subsubsection{Particular Concerns of the Current Operational Paradigm}

While there are a number of concerns over the current NPP operational paradigm, several stand out as particularly limiting in regard to maintaining a competitive presence in the U.S. electric market. These factors must be addressed if the operating nuclear fleet is to continue as a national energy source.

\subsubsection{Labor-centric vs. technology-centric}

NPPs have a large number of systems and components to address all electric-production and nuclear-safety concerns. These plants were designed back when automation was very expensive due to analog control technology and costly control and instrument cables. Thus, most plant components were designed for manual operation, whether putting them in or taking them out of service, repositioning them for different modes of operation, or conducting testing and maintenance. This resulted in large workforces for day-to-day operations compared to other forms of electric generation or other industrial sectors (e.g. manufacturing and process plants) in general.

In addition to the direct cost of labor is the huge and growing cost of maintaining a competent workforce while worker attrition continually erodes personnel numbers and their range of skills and qualifications. This problem is particularly acute in the nuclear power industry, where so much of the technology is outdated and no longer taught in engineering and technical schools. Thus, a much larger burden is placed on nuclear utilities to provide training on plant systems and components, whereas other forms of energy generation produced through modern plant technology can rely on general market skills when seeking qualified, competent employees. This applies to both initial and continuing technical training.

Greater reliance on human labor results in greater exposure to human error. Modern technological systems are orders of magnitude more reliable than human performance. Human error drives two kinds of costs. First, the direct cost is the consequences of whatever errors are made, such as decreased nuclear safety, loss of production, regulatory impacts, employee remediation, etc. Second is the large, costly effort to prevent human error, including specialized human-error prevention training, human-error prevention techniques at the job site, use of a second verifier for jobs performable by a single worker, etc. These types of costs are unnecessary when using automation to perform the same tasks.

\subsubsection{Highly specialized knowledge and skills needed on a part-time basis}

NPPs require highly specialized knowledge and skills driven by certain production, asset protection, and nuclear safety concerns. Under Nuclear Regulatory Commission (NRC) regulations, each nuclear facility operating license holder must maintain sufficient competency to ensure at all times that systems relied upon for nuclear safety meet their license-based Technical Specifications. This requires a deep understanding of the systems and components, along with all internal/external 
factors affecting their ability to perform their design-basis functions. These needs span many disciplines and areas of expertise, thus contributing to the large number of technical staff needed to provide the appropriate level of analysis and technical oversight. However, due to the rarity of certain problems, much of this expertise is only needed on a part-time basis, thus this level of expertise is sometimes underutilized, depending on whether it can be shared across multiple nuclear units. Added to this is the cost of maintaining such a high level of organizational competence; replacing experts who leave their positions due to resignation, retirement, transfer, or promotion; and waiting out the learning curve as replacement workers gain experience in those particular aspects of the plant.

\subsubsection{Staff located onsite due to short timeframe requirements}

Related to the need for highly specialized knowledge and skills is the need to have this expertise available on a very rapid basis in order to advise on whether certain systems and components are capable of performing their credited functions. This is particularly true of systems and components subject to the plant's Technical Specifications - systems and components that, if not fully operable, will cause station operators to take certain prescribed actions up to and including shutting the unit down and reporting to the NRC. Also, because so much of the plant is manual (meaning lack of remote instrumentation and other monitoring capabilities), these experts must often conduct observations in the field to make their determinations, thus compounding the need to be onsite - or available to come onsite - in a very short timeframe. Once again, this factor helps drive the need for a large, locally-based dedicated workforce.

\subsubsection{Industry Efforts to Reduce Costs}

Over the past decade, the nuclear power industry has recognized the need to reduce costs and therefore developed initiatives to achieve targeted savings in plant work activities without impacting nuclear safety. One such INPO-sponsored initiative, known as Industry Cumulative Impact Summary Report [10], emphasized that certain performance and behavior expectations had accumulated over time to the point of being burdensome in some situations. The initiative attempted to identify lowerrisk work situations in which these expectations could be relaxed to some degree.

Also notable was the NEI-sponsored Delivering the Nuclear Promise initiative [11], in which teams from across the nuclear industry worked to identify and document industry best practices for reducing costs while maintaining effectiveness and quality. These best practices were issued to the utilities in the form of efficiency bulletins, with some, by agreement of those utilities, designated for mandatory implementation while others were optional.

While these initiatives were certainly helpful in reducing costs and meeting targets, they did not result in positioning the industry for economic competitiveness in today's electric markets. Because of the nature of initiatives, some utilities reported that the majority of the savings were "soft," meaning they somewhat reduced costs for certain plant work activities but not in a way that fostered a reduced headcount. This was further evidence that the basic operational paradigm was constructed so work activities could be made more efficient, but that large categories of work could not be eliminated.

\subsection{Strategic Inflection Point}

Fundamental changes in the electric generation business have significant implications for the viability of U.S. commercial nuclear power in terms of the current business model. Many of these changes meet the definition of a "strategic inflection point," as described in the following section.

\subsubsection{Concept of a Strategic Inflection Point}

In 2014, Marc Lochmann and Ian Platts wrote an article for the Society of Petroleum Engineers entitled "Intelligent Energy: A Strategic Inflection Point" (SPE-170630-MS). In the article, they discuss the concept of a strategic inflection point as applied to the $O \& G$ industry, describing it as follows: 
A strategic inflection point is a time in the life of a business when its fundamentals are about to permanently change, where the old strategic picture dissolves and gives way to the new. That change can mean an opportunity to rise to new heights. But it may just as likely signal the beginning of the end. Companies either adopt the new ways of working or decline. This does not mean a catastrophic business failure has occurred; business continues but there is no going back if you intend to remain competitive. [12]

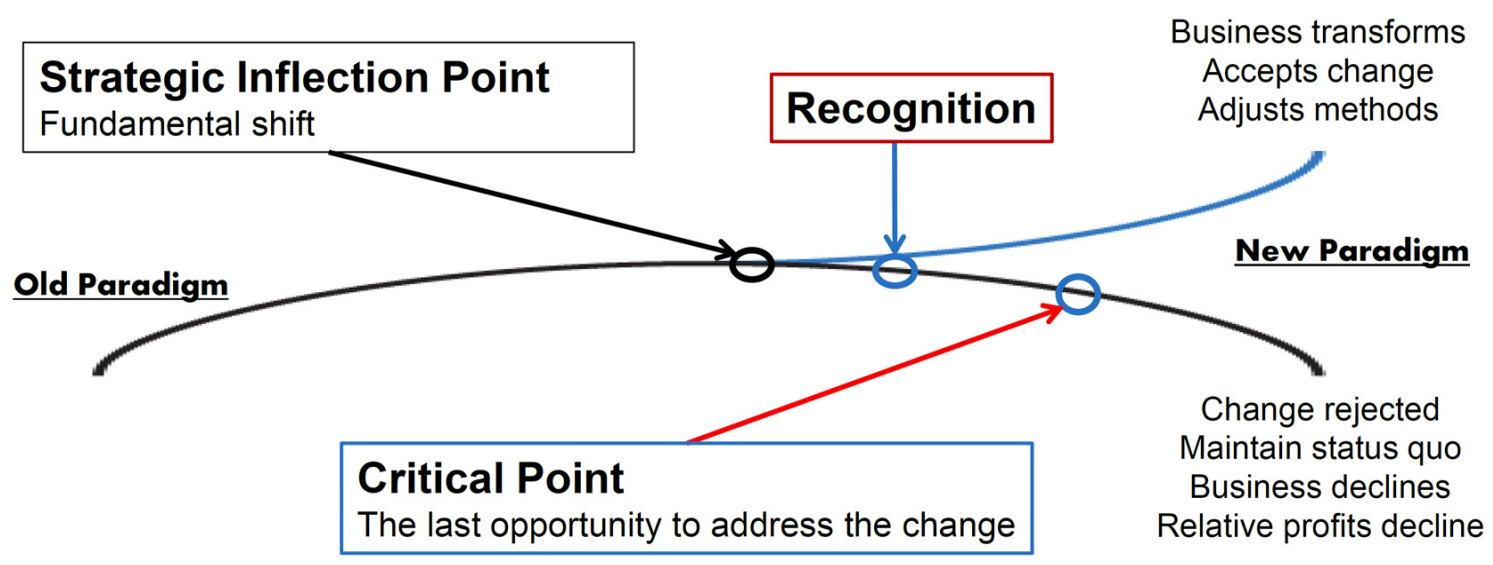

Adapted from: "Only the Paranoid Survive" by Andrew S. Grove

Figure 3. Strategic inflection point concept.

In this article, they reference Andrew Grove's book Only the Paranoid Survive [13], which introduces the concept of the strategic inflection point in the context of how his company, Intel Corp., was forced to recognize and react to fundamental changes in the computer memory business, leading to a transformation of their company and business model.

Lochmann and Platts list a number of factors that signify strategic inflection points, including:

- $10 x$ change in an element of the business

- Fundamental shift in the business or market

- What your business does now can be done differently

- What worked before does not work now

They went on to point out that many of the changes affecting the O\&G industry had the marks of strategic inflection points, and that the industry would need to undergo fundamental changes to survive in future global energy markets. One example was the introduction of shale-gas recovery technology (horizontal drilling and hydraulic fracturing) that led to an abundance of cheap natural gas and a historic decoupling of the prices for oil and gas.

Both Grove and the authors of this article point out that strategic inflection points are not typically recognized when they first occur, often being dismissed as passing fads by business insiders who say the changes will not significantly affect business operations. Often it is only in hindsight that the total alteration of the strategic course of the business is recognized. That said, the sooner recognition comes and the business model is adjusted to take advantage of the change rather than being victimized by it, the greater are the prospects for survival and the sooner the enterprise can plot a new trajectory for business success.

Conversely, businesses that dismiss strategic inflection points do not experience immediate consequences, as the overall effect within their market is still small. However, over time, the effect on these businesses becomes more and more apparent as they are materially impacted by new developments regarding market competition or other relevant factors. 
The authors also describe a critical point on the curve at which it becomes too late to make the necessary adjustments, usually because a business has reached the point of non-competitiveness and its cash flow is insufficient to make the needed investments to regain its market advantage. Such businesses, perhaps in denial, ride out their business models until they are simply no longer sustainable.

\subsubsection{Strategic Inflection Point for the U.S. Nuclear Fleet}

Certain factors are at work in the current energy markets that when combined, likely represent a strategic inflection point for commercial nuclear power in the U.S.

- Falling market price of subsidized renewable and gas electric generation - Market prices are often in the low $\$ 20 \mathrm{~s} / \mathrm{MWh}[14]$ when renewables are plentiful, and this is well below the production costs of most NPPs. At times, renewables can bid at negative prices, due to their strong production credit subsidies. There has been a 10x decrease in the levelized cost of energy for renewables from over the last two decades. This is in addition to the subsidies and preferred dispatch.

- Energy efficiency and new technologies such as LED lighting have significantly reduced load growth from what it would otherwise have been, curtailing the size of the electric market and increasing the competitive pricing pressure on nuclear power.

- Open electric markets - Many electric markets are now deregulated, and NPPs cannot simply be put into the generation mix by the owning utility. Even for regulated utilities, electric prices in deregulated markets put strong market pressure on what level of electric rates state utility commissions will supported.

- Devaluing of nuclear generation for baseload and ancillary services by deregulated markets - The contributions of nuclear as a form of large-scale, reliable, dispatchable generation, in addition to its ancillary services such as electric system stability and voltage/frequency regulation, are undervalued by the market, if compensated for at all. Sometimes, the market takes advantage of the difficulties involved in nuclear load following when these units operate at a loss during low-price periods while still providing the aforementioned grid-stabilizing services for free.

- Other electric generation forms are far more technology-centric than labor-centric. Over time, technology is generally a falling cost, whereas labor is a rising cost (despite productivity gains). Technology has allowed this generation of competitors to take advantage of ever-expanding modes of automation.

- Up to now, capital investment in the nuclear generation industry has largely focused on resolving regulatory-mandated nuclear safety issues rather than re-investing in facility modernization. Thus, NPPs are stuck in a business model based on 1960s plant technology, with an ongoing labor requirement from an era of more plentiful, less expensive technical skills and knowledge.

- Shrinking nuclear supplier base - As the nuclear industry continues to rely on declining technologies with little market value in other industrial sectors, it is increasingly difficult for qualified nuclear suppliers to continue these product lines without imposing substantial cost premiums. This has been exacerbated by the closure of some nuclear units, shrinking the market for qualified nuclear products and services even further. There is likely some minimum number of operating units below which the supplier market decline would greatly accelerate, followed by untenable price increases for the remaining operating units.

The combination and confluence of these factors signal a strategic inflection point for the U.S. nuclear operating fleet, something first evident around 2010. This is when nuclear units began to be excluded from auctioned markets as more renewables and gas-generation projects came online.

Notwithstanding government subsidies and preferences, the nuclear units were unable in some cases 
to compete head-to-head on the basis of price, due to the cost structure embedded in the current NPP business model. As mentioned, industry worked to reduce costs within the same business model, but this was insufficient to alter the basic competitive reality.

One strategy pursued by some nuclear operators was to obtain certain operating subsidies on the basis of nuclear's importance to local and state economies - particularly in terms of the number of jobs they supported and the tax revenue collected from those facilities. Another important consideration was its contribution to carbon-free energy production. These efforts have been successful in several states and fended off the premature closing of a number of nuclear units. However, these subsidies are finite, with no assurance of being extended; so, at best, they are temporary measures to bridge to a future time when nuclear generation can be competitive without them.

As suggested in the strategic inflection point model and business theory, to survive in such a business climate requires transitioning to a business model or paradigm that harnesses new realities rather than dismisses them. The clear, lasting solution would be a business model that is costcompetitive on its own (in light of all reasonable market forecasts) and sustainable on an ongoing basis. Properly formulated, it could address each of the factors contributing to this strategic inflection point.

Additionally, a partial solution lies in finding new markets for nuclear-generated energy that offer inherent advantages for large-scale, carbon-free energy sources. This concept, known as "integrated energy systems" [15] is currently being developed through the LWRS Program with several nuclear utility collaborators. In particular, NPPs have a natural advantage in producing both electricity and heat used in high-temperature electrolysis to efficiently create hydrogen. There is an emerging market for "clean" hydrogen, meaning hydrogen produced via a carbon-free process. Other innovative uses of nuclear energy to produce useful products exist, ranging from fertilizer to synfuels - all in a carbonfree process.

Taken together, these two solutions create a powerful combination of market opportunities that would ensure a very bright future for the U.S. operating nuclear fleet.

\subsection{The Need for a Transformed Business Model}

The combined effects of economic headwinds, diminishing returns in innovating the current business model, and the onset of a strategic inflection point for nuclear generation all point to the need for a transformed business model for nuclear generation - one that is technology-centric rather than labor-centric and simultaneously resolves current concerns over obsolescence.

It would be a great mistake to simply automate the current business model and thereby perpetuate business practices founded on manual, paper-based work processes. This would limit the full value and capabilities of digital technologies to just what is useful for automating heretofore manual work activities. While this is less disruptive and risky in the short run, it precludes more fundamental innovation for dramatically improving business performance and efficiency. One example that has already gained some acceptance is surveillance testing. A utility could improve the testing efficiency with smart procedures and work packages in a variety of ways. Or human involvement could be eliminated entirely by implementing advanced digital monitoring systems that conduct surveillance automatically and continuously.

That said, change cannot be disruptive to the point of being of detriment to nuclear safety and so it must be implemented in a deliberate, measured way.

\subsubsection{Critical Characteristics of a New Operational Paradigm}

The following are critical characteristics of a new operational paradigm that is both technically and economically viable as well as sustainable:

- Each NPP has the minimum staffing needed to carry out normal and routine plant operation and support activities plus address emergency situations. All other work needs 
are staffed for authorized work items on an augmented basis and only for the duration of the work. These resources are shared at the nuclear-fleet, corporate, or industry level.

- Work activities are reduced to the minimum for sustaining safe, prudent operations, eliminating those that do not add value to core business outcomes. Automation is used to eliminate workload requirements wherever feasible. Technology is used to assist multiskilled plant workers in areas where human expertise and skill are still needed, enabling higher work efficiency and reducing human error.

- A virtual plant support organization provides needed services and expertise on a part-time basis. Some of these functions are maintained within the utility if they are needed on a full-time basis. If not, they are outsourced to third-party service providers so costs are not incurred needlessly. The virtual organization uses advanced remote collaboration technologies to interface to plant functions and work activities just as seamlessly and effectively as if they were onsite.

- Plant maintenance and testing activities are organized in blocks or campaigns to consolidate work for augmented crews coming onsite to perform specific types of activities in the most cost-effective manner possible. Only urgent and minor types of maintenance and testing are performed on a short-term basis.

- Information is seamlessly shared across work activities, with no reentry or reformatting of data necessary. Data processing, data analysis, data reporting, and performance assurance activities have been largely automated using a common information model and AI technology. Information is continuously available on customized dashboards suited to specific work activities and management purposes with drill-down capability for deeper understanding. All cybersecurity concerns are effectively mitigated.

The new operational paradigm or business model must be formulated and sized to be competitive in future electric and/or derivative product markets. It must deliver dependable electric generation while adhering to all nuclear safety requirements and complementing the operational demands of a dynamic electric grid with a growing renewable component. It must be adaptable to future business opportunities and environments over a second — possibly even a third — operating license renewal period. Finally, it must continually represent a superior electric generation option and source of clean energy.

\subsubsection{Timeframe for Transformation}

Given that some nuclear units have already permanently closed down as a result of being noncompetitive, the need for this transformation could be immediate, depending on the specific case. Other units remain in a reasonably favorable situation and therefore have more time to restructure.

However, it will take time to fully realize this transformation. A five-year period to substantially implement it - with some functions taking longer - should be possible, depending on at least two major factors: (1) the continually falling price of renewables and (2) the possible expiration of electric rate subsidies granted by some states to keep their NPPs operating. Both point to the need for NPPs to compete in future electric markets all on their own, without being subject to changing public and political opinion. On the positive side, development of integrated energy systems such as hydrogen production could lead to an important role for nuclear generation in helping complement renewable energy.

Another consideration reflects the aging nuclear workforce. Utilities would prefer not to have layoffs, and there will be opportunity to attrite the workforce through retirements over the next five years if the transformational improvements can be brought online in a coordinated fashion. This would minimize the human toll resulting from such a transformation and help ease (the plants or the industry) into the new business model. 


\subsubsection{Associated Industry Restructuring}

Transformation of the nuclear business model will inevitably lead to business opportunities for nuclear industry suppliers in terms of providing technical services on an as-needed basis. Indeed, these types of services have always been a component of industry support, but here there might be new areas of service heretofore performed mostly by utilities in-house. For example, there are a number of successful instances in which industry suppliers - particularly for large nuclear steam supply systems - provide specialized services during outages, such as refueling operations or steam generator eddy-current analysis. In the future, the entire outage management function could be outsourced, including the year-round planning and preparation. This would be in keeping with the philosophy of staffing only for normal at-power operations.

There could also be some new service models in which suppliers relieved utilities of certain capital investments via lease arrangements, and in which suppliers assumed certain risks in exchange for performance incentives. The above example of outsourcing the entire outage management function would be a suitable candidate for such an arrangement, capping the utilities' risk of cost and schedule overruns, while providing appreciable incentives for on-target or superior performance.

Similar types of arrangements could emerge through nuclear operating company alliances. Selected organizational functions that might fit the criteria for third-party on-demand service could be pooled among the members of an alliance to create a cost-sharing arrangement less expensive than maintaining the equivalent capability within each operating utility. Prioritization of needs based on operational and regulatory urgency would need to be worked out. However, it is possible that such a pooled service could be more technically effective, with experts being exposed to a greater variety of issues and problems across the entire alliance.

To some degree, all these opportunities might result in an industry restructuring in which nuclear utilities no longer staff in-house technically complex functions outside normal plant operations. Rather, they would rely on trusted suppliers to perform these functions on an as-needed basis through advanced collaboration technologies that enable them to work as seamless extensions of the baseline organization. They would be authorized to use the same information network and work process applications as the utility. In time, the industry might evolve into using standard application interfaces that essentially enable suppliers to be "plug and play" directly with their utility clients, rendering company-specific interfaces unnecessary.

\subsubsection{Precedence for the Transformation}

Nuclear utilities are understandably risk-adverse in making large changes to how they operate and maintain NPPs. This is due to nuclear safety considerations, regulatory requirements, and electricgeneration production expectations. The current business model has been quite successful in guarding these outcomes, despite the market challenges these utilities now face.

However, as described in the preceding sections, there is a compelling rationale for why business model transformation, as opposed to continued incremental improvements, is now required. Still, this cannot and would not be undertaken unless these risks can be well-managed and, very importantly, the individual components of the transformation are affordable and provide suitable returns on investment. Further, the nuclear power industry does not like to be the first to attempt new ways of working, preferring instead that other industries first demonstrate successful transformations and resultant business success through the new ways of working. At a minimum, such assurances would require:

1. A proven methodology grounded in business and scientific principles

2. A proven track record of success

3. Phased implementation to ensure success and stability at every step of the transformation

4. A highly effective change-management plan and practices.

Fortunately, there are notable examples of industries being forced to make these kinds of fundamental business model transformations as a matter of survival — and succeeding. One such 
example is the concept of IO, introduced into the North Sea O\&G industry a couple of decades ago when the profitability of operating their fields was severely threatened by low global petroleum prices and the high overhead of operating offshore O\&G platforms. This effort resulted in significant changes to how these oil fields were operated, enabling the industry to continue to profitably operate their platforms. This has remarkable parallels to the U.S. commercial nuclear industry, as described in the next section.

\section{Integrated Operations}

As mentioned in the preceding section, IO was the driving concept behind the renewal of the North Sea O\&G industry. While this concept was developed and deployed by the petroleum operating companies themselves, they were substantially supported by Norway's IFE in developing methodologies and other resources. IFE has a rich history in researching nuclear operations, automation, and human factors and is a long-term collaborator with the LWRS Program. This relationship provides a direct pipeline of applicable knowledge and experience.

Also, following the success of the North Sea O\&G industry, IO has been adopted by a number of other industrial sectors, including other offshore oil operations, transportation, communications, and mining companies. It has become something of a discipline in and of itself, with a large body of research and operating experience publications from these adopters and from research and academic organizations.

Moreover, there are strong parallels between the North Sea O\&G industry and the U.S. nuclear industry in terms of a high embedded cost of production unsupportable by the market price of the energy product. Other parallels include being safety-critical, capital-intensive industries. These factors create difficult barriers to modernization, even if it is key to economic survival. However, IO has proven a successful path for revitalizing the North Sea O\&G industry, and it holds similar promise for the U.S. nuclear industry.

\subsection{Background on Integrated Operations}

The following sections are excerpted from a report prepared by the Institute for Energy Technology entitled Lessons Learned from Integrated Operations in the Petroleum Industry, IFE/F2019/079 [16], providing background on IO and discussion of the parallels to the U.S. nuclear industry. The full report is found in Appendix A and citations for text excerpts and figures used in this report are found there. This report defines IO as:

"Integrated operations (IO); refers to the integration of people, disciplines, organizations, and work processes supported by information and communication technology to make smarter decisions. In short, IO is collaboration with focus on production."

The concept of IO was developed primarily by international O\&G industries in response to decreasing revenues and increasing O\&M expenses. They were seeking ways to continue the safe operation of critical and complex offshore O\&G platforms while minimizing costs. Other industries utilizing IO include the mining industry, but our focus is on insights gained from O\&G industriesparticularly those involved in drilling and production on the Norwegian Conventional Shelf (NCS).

The IO concept is based on the availability of new technology — especially increased bandwidth allowing for new work forms and the sharing of data/information across great distances. 


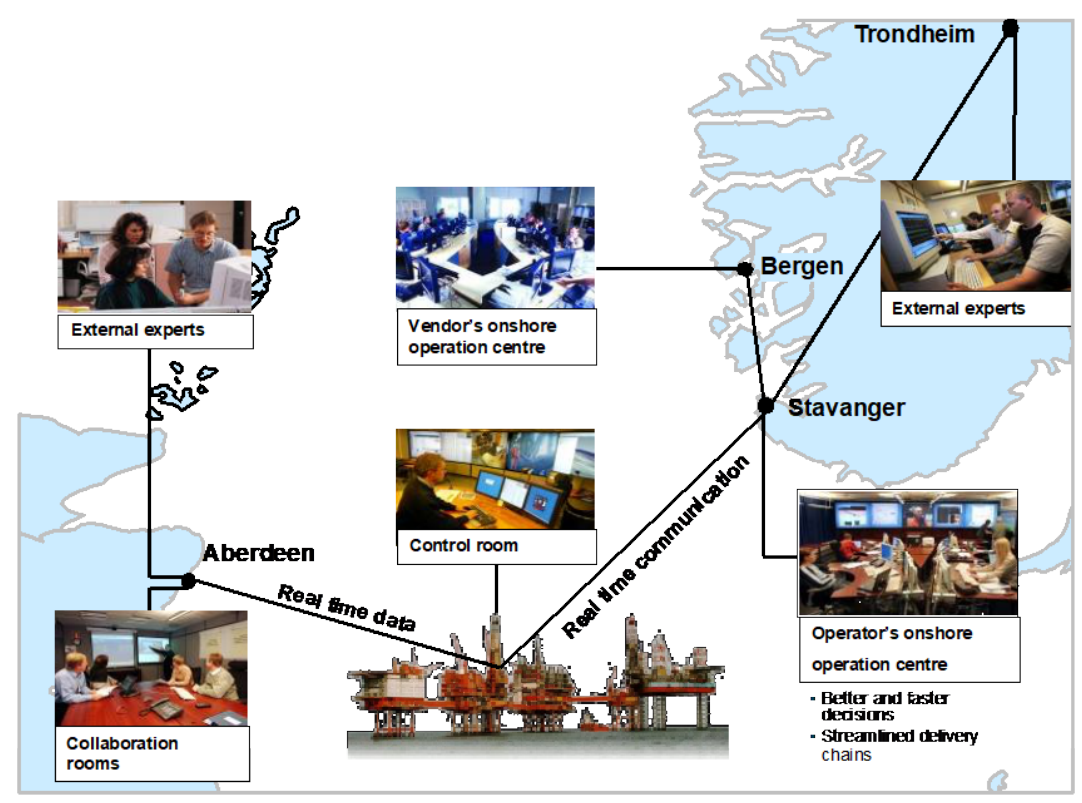

Figure 4. Concept sketch showing real-time data and communication as a basis of onshore support for offshore production and drilling installations.

IO is an approach for solving the challenges of having personnel, suppliers, and systems located both offshore and onshore as well as in different countries. IO is about removing the physical boundaries between people, making real-time cooperation across continents possible (Figure 4). IO involves using real-time data and new technology to remove the divides between disciplines, professional groups, and companies. It is about how information technology that makes remote operations possible can form the basis for new, more effective ways of working. Real-time transfer of data over long distances can eliminate the physical separation between installations at sea and support organizations onshore, between different professional groups, and between oil companies and suppliers.

When working across professional boundaries and exploiting real-time data and technology for removing such divisions as time and place, the aim is to ensure better value-creation for the future. Some of the benefits of IO are as follows:

- Improved occupational health and safety

- More efficient operations

- Better reservoir and production control/optimization

- Better monitoring of equipment and more efficient maintenance

- Better resource exploitation

- Increased regularity (uptime)

\subsubsection{North Sea Oil and Gas Industry Experience}

The Norwegian oil industry has a long history of cooperation. In autumn of 2004, the Norwegian Oil Industry Association (OLF) decided to implement an industry-wide IO program in the form of a new self-service concept for remote, real-time management of O\&G fields on the NCS. The decision was based on recommendations from a feasibility study indicating that IO could reduce operating costs by $20-30 \%$ and accelerate production by $5-10 \%$ through:

- Improved decision-making and work processes via IO implementation and the transfer of operations to virtual operation centers onshore 
- IT solutions that support remote, real-time management of drilling operations, reservoirs and production facilities, maintenance, and logistics.

The program's main goals were to establish a common digital infrastructure for Norwegian offshore facilities, industry-wide information security requirements for accessing this infrastructure, common standards for transferring data from offshore operations to virtual operation centers onshore, best practices for remote and real-time management of O\&G fields, and a knowledgeable industry supportive of IO.

The value potential of IO was estimated in the form of increased recovery rates, increased and accelerated production, and reduced costs. The estimates are based on documented results from implementing IO measures in comparable fields, as well as conservative estimates of the effects of measures yet untried.

In total, this gives a realistic estimate of IO's value on the NCS. The effects of IO will create added value in regard to those measures upon which the fields based their cost development and recoverable reserve estimates. It is this added value that has been quantified.

The value potential estimate was based on information made available to the project from the operating companies. The information mainly consisted of forecasts reported to the Norwegian Petroleum Directorate, forecasts for operating and capital expenses and field-specific information submitted in meetings with field management.

The study concluded that IO represents a potential net present value (NPV) of U.S. \$40 billion. The basis for the estimates was a discount rate of $7 \%$ and the price trajectory indicated in the national budget (NB2006), which was based on an oil price of $\$ 55$ per barrel-a price that fell to $\$ 34$ per barrel in 2015.

The main contributor to the potential value is accelerated production resulting from increased reserves and production optimization. The total reserve increase equals a large new field on the NCS. Costs associated with realizing this value were estimated at $\$ 2.5-3.5$ billion (NPV) over a 15 -year period.

Realizing these values was assumed to be dependent upon aggressively implementing IO on the NCS. If the companies cannot carry out this implementation rate, the values would be significantly reduced. If the companies choose a slower but focused implementation strategy, the IO's value will be $\$ 25.6$ billion (NPV) - $\$ 14.4$ billion less than the estimated potential value. Costs related to such an implementation are estimated at $\$ 2.9$ billion (NPV).

\subsubsection{Continuous Development of the IO Concept}

In autumn of 2005, a work group established by OLF - along with representatives from major oil companies, licensing authorities, and Norwegian energy research institutes such as Halden - delivered a report that became the guidance for implementing new work practices. The report established scenarios for the implementation and predicted that IO would most likely be implemented in two stages: Generation 1 (G1) followed by Generation 2 (G2) processes (Figure 5). Both generations were assumed to be game-changers for existing work processes. 


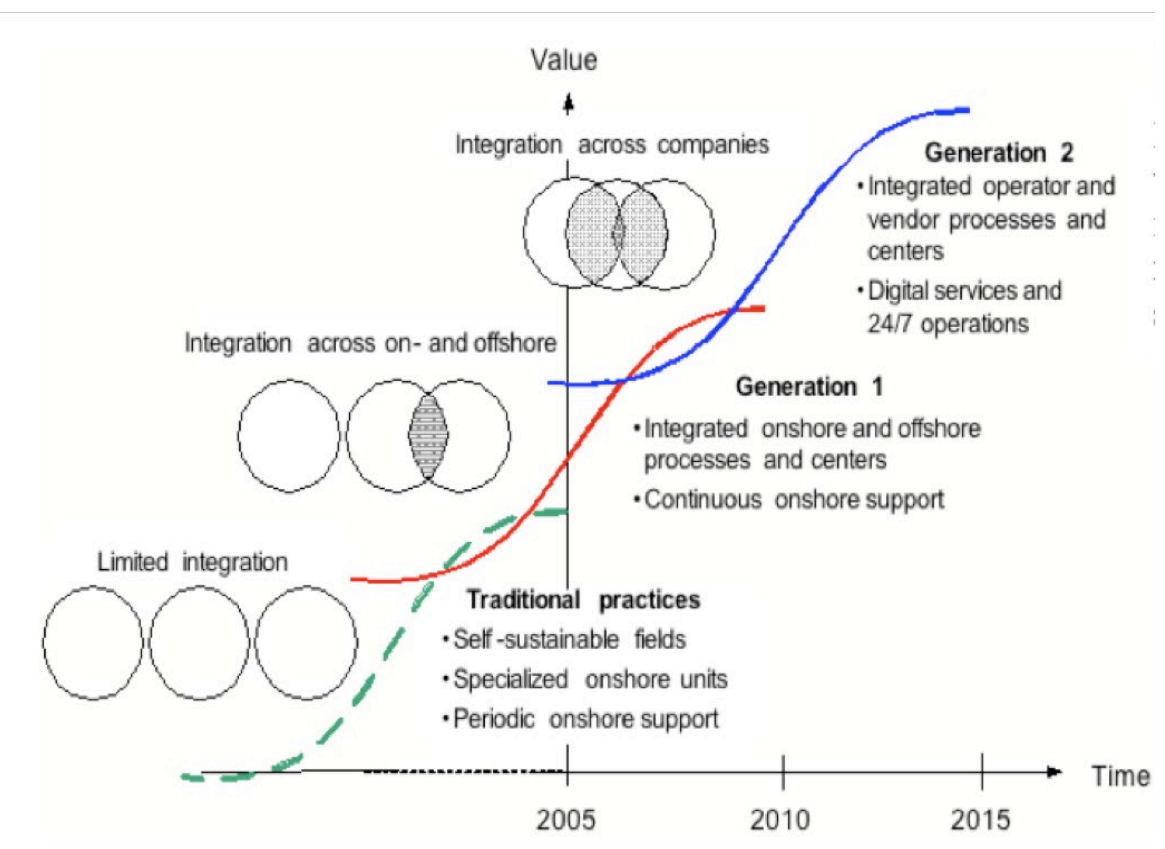

Figure 5. OLF prediction for the two steps in IO implementation.

The following sections describe the progressive development of IO practices over the years.

\subsubsection{Traditional practices}

Changes to traditional practices were already seen in 2005 due to the burgeoning implementation of G1 processes, but prevailing practices still had limited focus on integrating work processes across disciplines, between onshore and offshore facilities, and across companies.

Description of traditional practices:

Generally speaking, most operational decisions are made offshore, in isolation or with limited support from experts onshore. Plans are relatively rigid and primarily changed at fixed intervals. The organizational structure is traditional, meaning that personnel onshore and offshore belong to several different units with different goals and key performance indicators. Plans were made and problems solved in a fragmented manner. Basic as well as advanced education/courses aimed to develop disciplinary specialists, not professionals with a good understanding of value chains and work processes. IT systems were specialized, and it was difficult and time-consuming to gather the data necessary to optimize the processes. Existing practices supported integrated work processes to a limited degree.

\subsubsection{First-generation IO (G1) processes}

By mid-summer of 2019, not many fields still operated based on the traditional practices. A major shift had taken place when Equinor (formerly Statoil, by far the biggest operator on the NCS) implemented a new operation model in the summer of 2009. Most main features of work practices forecasted in the integrated work processes report were implemented or are currently under implementation. The same is true for the other operators on the NCS, though to a slightly varying degree. Practices to be implemented were assumed to differ from company to company, but common to all were the following:

- They are built around onshore centers closely integrated with offshore operations through collaboration facilities and solutions that secure personnel onshore/offshore access to the same information at the same time, thereby facilitating real-time collaboration.

- The centers are staffed by professionals with the competencies necessary to manage the field(s) in question and make the necessary decisions. 
- For some areas such as drilling, onshore support is available 24/7; for others, normal work hours apply (e.g., 6 a.m. to 6 p.m.).

- Personnel both onshore and offshore can monitor operations in real-time, compare actual data with simulations, and identify operational as well as safety-related problems.

- Professionals in the onshore centers can carry out "what-if" analyses, discuss the consequences of various decisions, integrate activity plans, and communicate with personnel offshore through high-fidelity audio/video systems and portable computers to learn what can be done to further optimize operations, integrate plans, and avoid or solve problems affecting production, costs, and safety.

- The team was delegated the necessary authority to make decisions.

Implementations of these practices - termed "G1 integrated work processes"-were expected to lead to relatively simple but profound changes to traditional work processes.

\subsubsection{Second-generation IO (G2) processes}

Implementation of G2 IO is expected to lead to closer integration of operator/vendor work processes and - most importantly to the fields - development of "digital services" (i.e., operational concepts based on delivering a large portion of the services required to operate a field "over the net":

- A typical O\&G field will then be operated by personnel located in operation centers belonging to both the operators (oil companies) and vendors.

- The vendors will take over some of the daily work and decision-making processes earlier carried out by the operators (e.g., monitoring, analyzing, and optimizing tasks) and will digitally deliver services to the operators in real-time "over the net."

- Personnel offshore will be informed and advised when anomalies or alarms are registered.

- Personnel offshore will still take overall responsibility for operating the fields on the NCS and will make the necessary decisions to handle anomalies or alarms.

The centers will be operational 24/7 and, to avoid information overload, make extensive use of tools for automatically filtering information and automating processes and decisions. Advanced automatic optimizers will, for example, manage daily production safely and efficiently.

The teams that staff these centers will be geographically dispersed across Norway and around the world, carrying out tasks in accordance with "follow the sun" principles. The team members will have full access to required information, tools, services, and each other through advanced decision-support and collaboration tools. To ensure that team members collaborate efficiently, goals will be wellaligned and performance measured according to the same key performance indicators. This will have a major effect on key work processes.

\subsubsection{Adoption by Other Industrial Sectors}

The petroleum industry pioneered IO and established its scientific and theoretical base through a plethora of studies and reports. Based on these studies, other industries adopted IO methods and processes to improve their safety, productivity, and profitability. The mining industry is a good example of how IO can be adapted to a unique situation.

The mining industry is in a position similar to that of the O\&G industry, with lower productivity, reduced quantity and quality of the product (ore) and increasing labor costs all challenging its economic viability. They were looking for a new outlook/approach to generate solutions. Many large mining companies adopted the IO model, both to transform existing mines and develop green field projects.

A good example of how one mining company applied IO is found in the Australian mining giant, Rio Tinto. Over 10 years ago, they kicked off their Mine of the Future program and, alongside it, an 
operations center in Perth, Australia for the company's iron ore business. Rio Tinto's iron ore business includes 16 iron ore mines, $1,500 \mathrm{~km}$ of rail, three ports, three power stations, and a water and sewer system spanning a large geographic area.

Combined, its operations generate 2.4 terabytes of data every minute from hundreds of pieces of mobile equipment and sensors providing real-time location and condition monitoring. Rio Tinto's former CEO, Sam Walsh, said the company's operations center revolutionized how the industry approaches integrated mining, turning 16 individual mines into one integrated mining processing and logistics system controlled by operators $1,500 \mathrm{~km}$ from the physical sites.

Ten years ago, Rio Tinto introduced fully autonomous haul trucks as the first step in its Mine of the Future program. The autonomous trucks reportedly lowered fuel use by $13 \%$, reduced accidents, and eliminated the need for workers to be stationed in remote areas.

Emphasizing the necessity of considering any transformational effort in the context of four critical areas (process, technology, people, and governance), Walsh said, quoting Bill Gates, "The first rule in any technology used in a business is that automation applied to an efficient operation will magnify that efficiency. The second rule is that automation applied to an inefficient operation will magnify the inefficiency."

As another example, the airline industry utilized elements of IO to improve business safety, efficiency, and profitability. Major airlines rely on IO Centers to manage scheduling, weather forecasting, booking, and maintenance. Some engine suppliers implemented online performance monitoring to predict engine failure via advanced algorithms and big-data models. Using these predictive models enables preventive maintenance based on the condition of the engine rather than on a fixed schedule. This improves the economic and safety performance of the fleet.

\subsection{Parallels to the U.S. Nuclear Industry}

Increased productivity and value creation through IO implementation basically boil down to designing custom capabilities that contribute to more efficient work execution. The enabler for IO is data communication and digitalization, allowing one to work remotely with more efficient tools. In principle, this opportunity is the same for all industries, but different industries operate under various environmental frame conditions, regulatory regimes, and business cultures that can make it easier or more difficult to realize gains. In this regard, it is clear that Norwegian offshore O\&G production and U.S. nuclear electricity generation have more similarities than disparities.
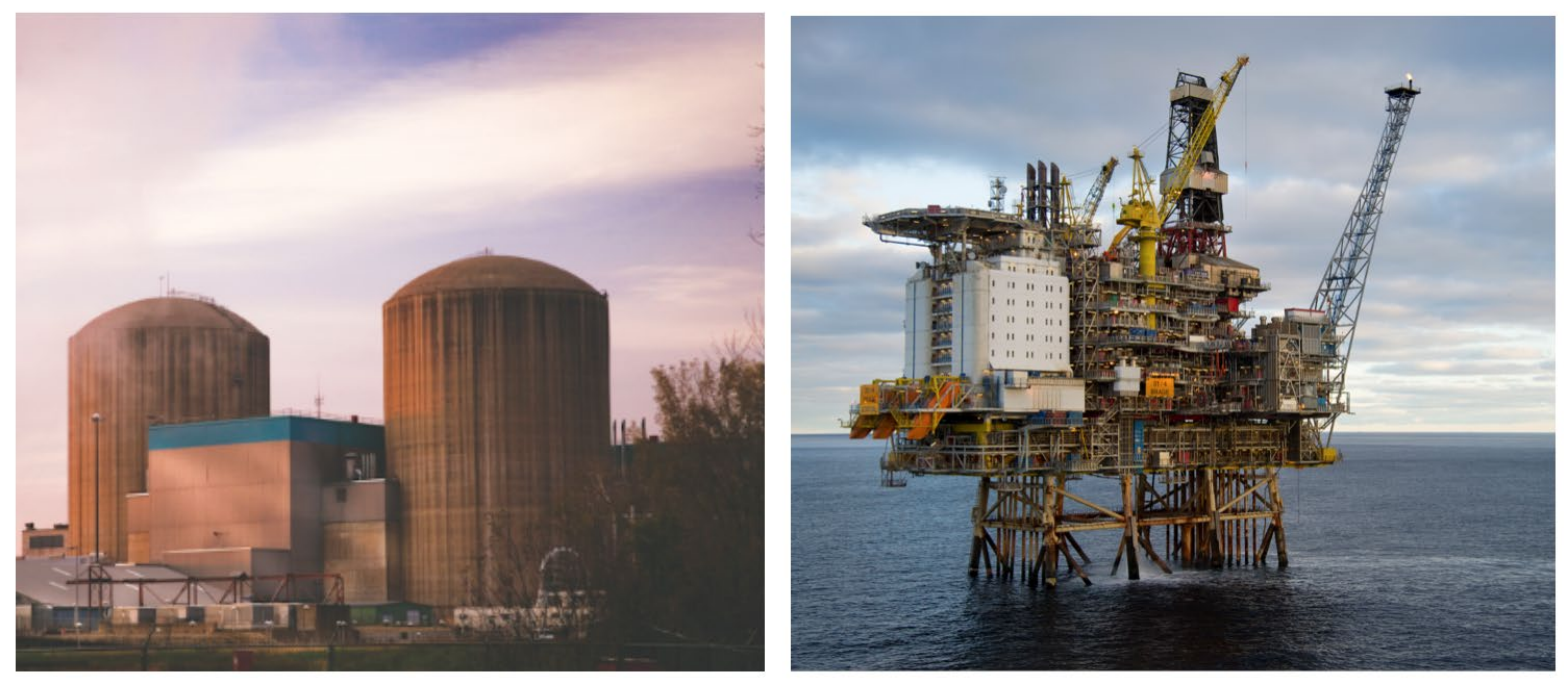

Figure 6. (Left) Xcel Energy's Prairie Island Nuclear Generating Station, Minnesota. (Right) Wintershall Brage oil production platform, Norwegian Continental Shelf. 
There are obviously differences in environmental contexts, production processes, and the physical layouts of the plants (Figure 6). The physical design of an oil platform is very much about saving space and weight, but formal requirements for the design process and approved equipment are not so different from the case of nuclear power. Note that human factors and work system standards and guidelines applied by the Norwegian O\&G industry were mainly inherited from the nuclear domain.

\subsubsection{Continuous Operation Production Facilities}

Not surprisingly, there are a few differences in management structure and craft disciplines, and seemingly little difference in how maintenance is organized and work tasks are divided up and performed by I\&C (automation), electricians, and mechanics.

Both drilling and production rigs operate $24 / 7$, with a focus on minimizing downtime and/or reduced production. This matches the goals of a typical NPP. In addition, both industries have very precise maintenance and outage repair windows for maintaining major equipment, installing new equipment, and performing tests. Planning and scheduling are absolutely critical for executing work and avoiding impacts to production and safety limits.

\subsubsection{Geographically Distributed Production Sites}

Both oil/gas offshore platforms and NPPs are geographically dispersed from corporate headquarters and population centers due to being on the oil/gas fields or requiring suitable site features (land, water source) to support nuclear operations and related facilities. In both cases, production at the company or fleet level cannot be geographically consolidated, and substantial infrastructure is needed at each production facility.

\subsubsection{High Safety and Environmental Risk}

Due to the high consequence of failure-illustrated by accidents such as Three Mile Island, Piper Alpha, and Deepwater Horizon - both industries have zero tolerance for accidents or personal injury. Safety requirements and the technical complexity of process control systems are high; accordingly, inhouse competencies and capacities in these areas must be maintained at a high level. Delving further into this area, both industries feature similarities in:

- Safety planning

- Risk detection

- Operational safety focus

- Procedural control and alarm handling

- Emergency training

These industries also share similarities in how they go about their day-to-day operations. Centralized control rooms in both industries have similar functions and functional divisions, and their ways of conducting monitoring, alarm-handling, and process control are much alike (Figure 7). However, the high degree of digitalization in NCS control rooms gives each operator better situational awareness, eliminating the need to populate the central control room with more than the typical maximum of 4-5 operators for large installations, and possibly as few as two operators for the most modern installations with a high degree of automation. 

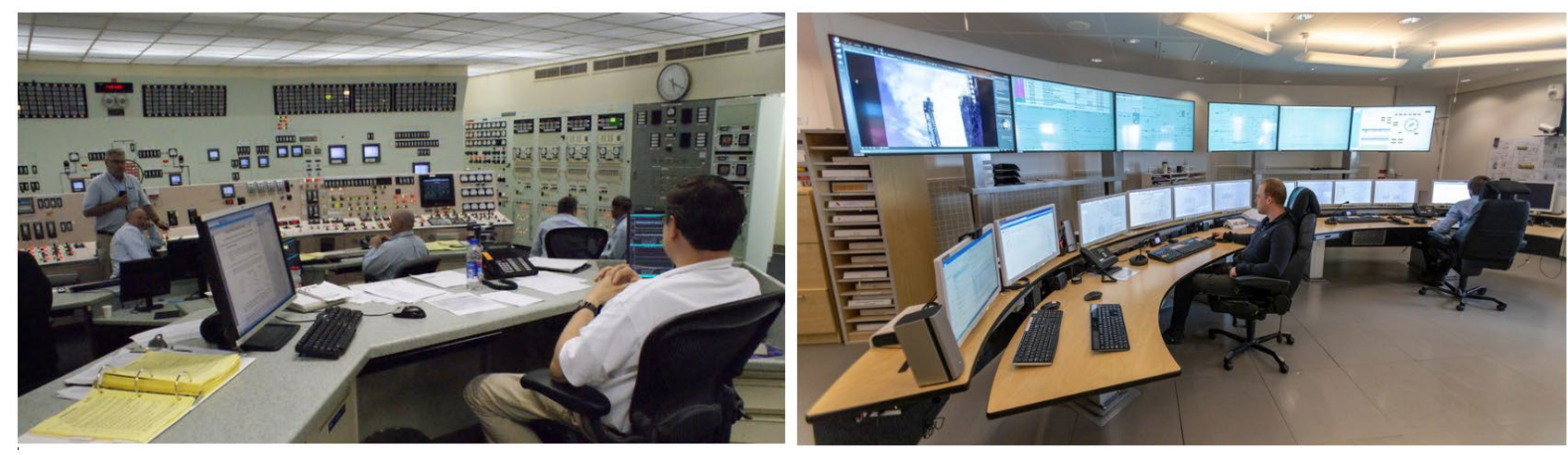

Figure 7. Illustration of a typical U.S. nuclear plant control room (left) and a modern petroleum control room (right).

\subsubsection{High Level of Technical Expertise and Technology Required}

While the technologies and related technical expertise involved are considerably different, both industries rely on advanced technologies that require considerable organizational technologymanagement competencies. The O\&G platforms are involved in deep-water drilling, constructing and maintaining all facilities that bring the oil/gas to the surface, then transporting it to shore.

Nuclear power generation is also highly technology-dependent, with large nuclear reactors, sophisticated control systems, and numerous other engineering and scientific challenges.

\subsubsection{Performed in Potentially Challenging Situations}

Petroleum products are highly volatile and pose a danger to the crew and platform. Additional danger is presented by the drilling and production equipment used during operations. Further, the platforms themselves are located in a dangerous environment, with storms and other challenges due to being isolated in the North Sea-in some cases, even above the Arctic Circle.

Similarly, NPPs must manage numerous dangerous hazards, such as high-energy steam piping, radioactivity, nuclear contamination, chemicals, and high-voltage power. Engineering controls and worker protections are integral to all work practices in both industries.

\subsubsection{Public and Regulatory Scrutiny}

Both industries are highly regulated in terms of protecting public safety and health, not just employees and facilities. In addition, various regulatory requirements provide environmental protections against oil spills and radiation release.

Both industries have been shaped by notable accidents: Deep Water Horizon for the O\&G industry and Three Mile Island for nuclear power. In fact, two other consequential NPP accidentsChernobyl and Fukushima Daiichi-also entailed regulatory responses and shaped public opinion, despite not having occurred in the U.S.

These accidents made the public very wary of environmental concerns regarding everything from offshore drilling and petroleum production to the location and acceptability of NPPs. The pending shutdown of the Indian Point nuclear plant is largely due to eroded public and political support as a result of being in such close proximity to New York City. So, for both industries, regulatory performance and positive public relations must be ensured in all aspects of operations.

One notable difference between the two industries is the U.S. nuclear industry's voluntary selfassessment and standards re-enforcement through its development and sponsorship of INPO, later expanded to a companion international organization known as the World Association of Nuclear Operators. Rapid reaction to operating experience across the nuclear industry, along with industrywide adoption of best practices, has resulted in unparalleled safety and production achievements for the U.S. nuclear industry. In fact, the O\&G industry pointed to this as something that was lacking in their industry following the Deep Water Horizon accident. 


\subsubsection{Challenged by Market Conditions}

The price of oil as a worldwide commodity is subject not only to market forces but also geopolitical events that threaten the supply. In fact, the supply is artificially set by national and cartel organizations by simply varying their production rates. The cost of production, and therefore the operating model, for any operator must generally be within the market price - at least over the longerterm-not withstanding some temporary low-price fluctuations resulting in an oversupply.

Nuclear generation over the past two decades has been increasingly subjected to similar market forces, such as the abundance of cheap shale-gas generation and, at times, oversupply of subsidized renewable energy with mandated priority in the market due to political actions. While there have been state-level rate subsidies for certain operators in recent years, nuclear power must be able to compete on its own to be economically viable over the long-term. Improvements in energy storage, such as high-capacity batteries, will enable deeper penetration of non-dispatchable renewables into the electric generation mix, thereby eroding the need for baseload and back-up power generation such that provided by NPPs.

An additional similarity between the two industries is that they are capital-intensive and require long investment-recovery periods. It is very difficult to attract investors in light of these market conditions, with no way to accurately predict the price of the product over the long-term, due to emerging energy technologies, political changes, and environmental concerns. Again, a lean, low-cost business model is the best hedge against erosion of the value proposition for these long terminvestments.

\subsection{Integrated Operations Key Operational Concepts}

The following section describes the key operational concepts of IO that are considered transferable to the U.S. nuclear industry in developing a transformed nuclear operating model. It should be noted that the nuclear industry has experience with each of these concepts - at least on a limited basis. However, they have not been exploited to their full potential as envisioned in IO, nor have they been combined to enable a transformed operating model for nuclear generation.

\subsubsection{Collaboration}

The most visible aspect of IO is its collaborative environment: a suite of rooms customized to support real-time communication and information exchanges between two or more locations. All companies operating on the NCS today have built collaborative environments in which groups use a single information source and real-time communications capability for joint decision-making.

However, not all these environments are equally successful at delivering benefits. Many companies derive some value by effectively collaborating in single-discipline (vertical) operations such as well-integrity or rotating-equipment monitoring. Verticals also scale well across assets. However, succeeding at cross-discipline (horizontal) operations such as maintenance is far more challenging, requiring coordinated actions across multiple disciplines and physical locations.

In developing its IO-based model, Equinor (formerly Statoil) established a vision for the organization, along with concrete objectives for how future operations should be carried out. Conceptual frameworks utilizing the underlying mechanisms behind the new work methodology are depicted in Figure 8. 


\begin{tabular}{cc}
\hline $\begin{array}{c}\text { Traditional way of } \\
\text { working }\end{array}$ & IO way of working \\
\hline Serial & Parallel \\
Single discipline & Multi discipline \\
Dependence of physical & Independence of physical \\
location & location \\
Decisions are made based & Decisions are made based \\
on historical data & on real-time data \\
\hline Reactive & Proactive \\
\hline
\end{tabular}

Figure 8. General development and digitalization change how work is performed.

\subsubsection{Staffing According to Activity}

Activity-dependent staffing means that resources for larger activities such as drilling and projects are provided by a resource pool or other parts of the company. Typically, such pools deliver skilled workers for activity-controlled staffing. The resource pool manages the company's competencies within selected subject areas.

The same concept is used to ensure resources for planned maintenance across different platforms in a given area. Establishing a pool of maintenance resources can effectively reduce maintenance backlogs in prioritized areas. Coordinated prioritization across fields ensures that maintenance resources are fully utilized in their respective operating areas. This way of prioritizing resources must be based on regularity and maintenance analysis.

For the start-up of new systems or green field installations, it is effective to plan according to a fixed minimum staffing along with additional start-up staffing that will gradually be reduced once production stabilizes.

\subsubsection{Campaign-Based (Block) Maintenance and Modifications}

Campaign-based maintenance is a resource-effective way of handling planned and preventive work. Examples include carrying out major activities such as drilling or projects, as well as applying extra resources due to audit shutdown, extraordinary training, etc. The need for additional staffing should be assessed and approved as part of the decision to carry out the activity. Simplified Maintenance

One major NCS operator implemented the promising concept of increased flexibility in performing low-risk, low-complexity maintenance. This was done, in part, to reduce bureaucratic involvement in planning, starting, and finishing such work. By identifying short-duration, low-risk jobs and then running them through a simplified work process, time can be saved in each administrative phase of the job.

\subsubsection{Multi-Skilled Staff}

There are many situations in which multi-skilled workers can considerably contribute to operational efficiency. Several IFE projects for a major NCS operator-projects involving function reallocation and workload studies - identified numerous situations in which the combination of field operators, I\&C, and electrical disciplines offers potential efficiency gains.

However, earlier attempts at cross-training in an NCS-company developing the so-called PEMA (process, electro, mechanics, and automation) operator stalled due to lack of industry-wide agreements and the challenge of re-training within multiple disciplines. To make the solution work, the implementation requires a sufficient volume of replacement personnel in case of turnover and sick-leave. Combining only two disciplines is easier and would give a lot of flexibility in utilizing staff for day-to-day work; even then, training and updating competencies within multiple crafts would take more time than desired. 
The solution may lie in differentiating between "multi-craft" and "multi-skilled." The concept of "multi-craft" training would be defined as being a Journeyman in one trade and achieving Journeyman status in another trade, whereas "multi-skill" training would be defined as being a Journeyman in one trade and merely adding limited additional skills from another. Obviously, the investment in time and resources for multi-craft training is far greater than for multi-skill training. In addition, the difficulties in maintaining proficiency are far greater for multi-craft training, and this could negatively impact both safety and productivity. It appears that most organizations are moving toward multi-skill training.

Analysis has shown that field operators on a modernized production platform will have approximately half their time available for emergent tasks. Given the fact that a high proportion of field operators on the NCS have Journeyman papers from either the mechanics, electro, or I\&C disciplines, many of these operators possess the competence to perform many work tasks within their secondary disciplines without the need for continuous updating of competencies and training.

\subsubsection{Offsite Monitoring by Equipment Vendors}

Using their own servers, the on-board computer network, and onshore fiber-optic cable, thirdparty suppliers can log in to offshore equipment from their own offices. This enables condition-based maintenance and the ability to troubleshoot errors or provide remote support, potentially resulting in significant savings. From the office, one can solve software errors and discover user errors without traveling offshore. In the case of equipment failure, one can determine the problem and what parts need to be included for service assignments offshore. This means there is no waiting offshore for the right part to be sent out. There will be fewer trips with shorter stays using this technology.

Despite increasing examples of successful multidisciplinary operation centers, business incentives for closer integration with vendors, along with vendor monitoring of equipment, are not strong enough to achieve a breakthrough in the industry. Successful examples (e.g., valve monitoring) are by no means widespread. Instead, we have seen a steady build-up of analytic capabilities to handle equipment-condition monitoring within the O\&G companies' onshore operation centers. For Equinor, this monitoring capability is the driving force behind their ongoing digitalization programs.

It is reasonable to think that success stories of third-party remote monitoring are strongly connected to how operator companies establish incentives. Remote monitoring will reduce unnecessary offshore waiting times in regard to parts, work packages, and dependency on other jobs. The result is reduced costs and fewer offshore days for the operator company. But how will this affect the supplier? It is common for offshore working hours to be invoiced according to so-called "reimbursable contracts." By working more efficiently and having fewer staff offshore, contracting companies miss out on a possible profit opportunity. Experience shows that, to establish sustainable models based on this concept, the operator and supplier must together invest considerable capital funds in establishing the operation centers. Since operation from the supplier's center can also entail a contractual lock-in for the oil company, a great deal of trust between parties is required.

\subsubsection{Bring the Problem to the Experts}

Traditionally, O\&G companies (operators and service companies alike) kept all their expertise inhouse and categorized into asset organizations. The traditional organizational model of having one individual expert assigned to each asset is not very efficient because, at any one time, an inexperienced individual may be struggling a given problem while an experienced individual is rotated to an asset team in which the problem occurs very rarely. This model fails to make effective use of the company's expertise. 


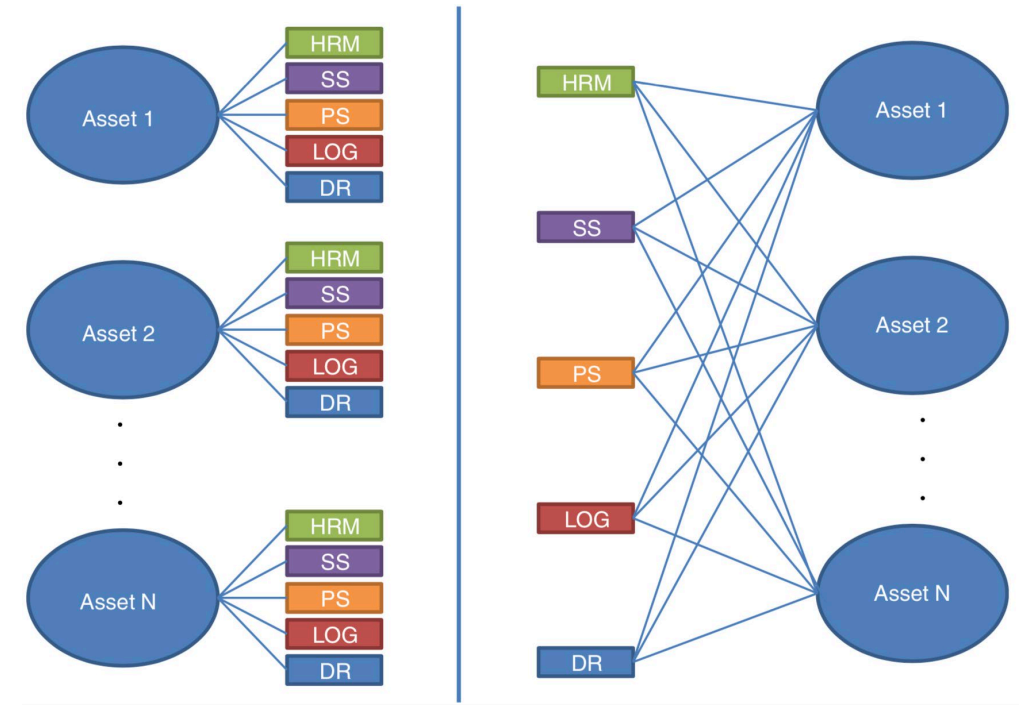

Figure 9. The basic principle behind IO. (Left) An illustration of self-supported fields. (Right) Shared expertise across fields. HRM, SS, etc., are different functional areas.

In considering the staffing impact of changing the operating model (see Figure 9), an example is referenced from an unpublished IFE study performed for a major NCS operator, with the as a functions of the company being reorganized according to the right sides of Figure 9. The study estimated the overall manning needs of a new offshore installation. A total of 13 different in-house, onshore support centers were identified as delivering services to the particular offshore installation. The centers were spread out over seven different geographical locations throughout Norway. In the study, 70 different specialized competencies or functions were identified Of the different competencies, 51 were given time estimates regarding their level of support to the specific offshore installation. The total delivery to the offshore installation from these 51 competencies was approximately 30 Full-Time Equivalents (FTE), ranging from 0.1 to 2.2 FTE per discipline. Since six of the 51 competencies delivered more than one FTE, the minimum number of people involved in support delivery had to be 57. Using IO and changing from a traditional self-supported field to expert centers (again, see Figure 9), resulted in a theoretical savings of 27 FTE. However, this theoretical savings would be reduced for competencies delivering only a fraction of an FTE and for those that could be rotated between fields or locally serve multiple offshore installations by the hour.

\subsubsection{Collaboration between Operators and Contractors}

A major challenge for realizing the improvement potential is the contractual relationship between the contractor and the oil company. Issues include:

- Lack of key performance indicators (KPIs) and incentives to support the desired work methods

- Few initiatives for local middle management to adopt new ways of working with contractors

- Incompatibility of IT systems and collaboration technology

- Disagreement over who will bear the cost for establishing the collaboration solutions

- Lack of contractor culture of innovation regarding their business models

One idea for overcoming these challenges is to incentivize contractors to deliver more services in accordance with IO principles. To succeed this holistic approach, all success criteria must be fulfilled. In addition, the holistic perspective must transcend contractual barriers between parties. Operators must take the lead in creating an environment of trust in which innovative IO-based delivery models are valued. Contractors must be able to differentiate themselves by proposing new ways of working and collaboration to create win/win situations. KPIs and compensation models must be adopted and a shared improvement agenda established. 


\subsection{Integrated Operations Method}

The following are the four key steps in applying the IO method to transform the operating model of a large enterprise as defined in the report The Capability Approach to Integrated Operations Handbook [17].

\subsubsection{Setting Operational Context}

This step consists of identifying the operational context in terms of both opportunities and constraints regarding capability development. Factors would include market opportunity, market pricing, corporate business objectives, etc. Constraints would include regulatory requirements, industry standards, technological limitations, public opinion, community relations, etc.

\subsubsection{Identifying Key Capabilities}

In general, a capability is the ability to perform a particular task or activity. Operational capabilities pertain to the current operations of an organization and enable that organization to perform its necessary tasks. This resource base includes tangible, intangible, and human assets. Further, it may include resources that the organization can access but does not necessarily own. When referring to the O\&G industry, we can broadly categorize the organization's resource base into four types of assets: people, processes, technology, and governance/organization.

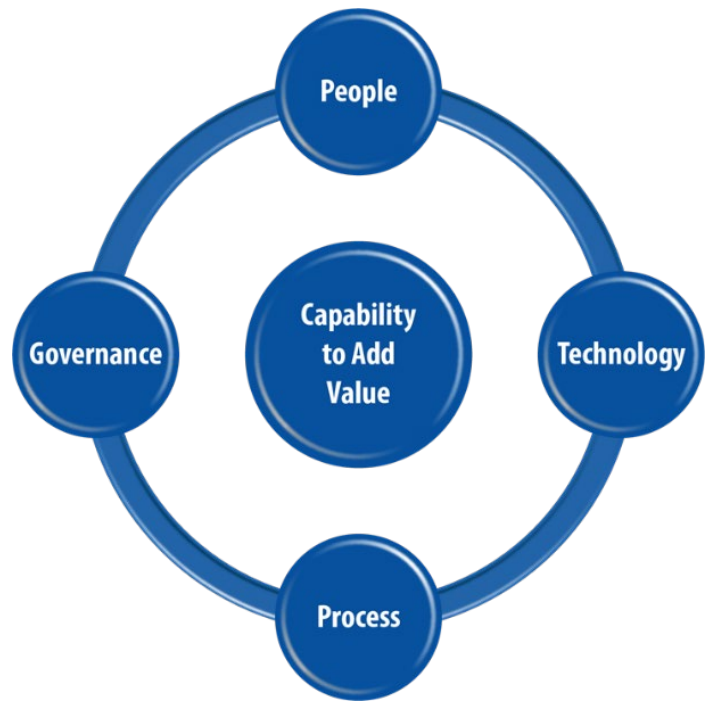

Figure 10. A capability is the synthesis of interdependent resources involving people, processes, technology, and governance - all enabling the direct creation of added value.

\subsubsection{Sub-Layering Capabilities}

Sub-layering capabilities consists of identifying the major functional areas of the capabilities and, within these functional areas, the work processes for accomplishing the specific objectives of the capabilities. These functional areas are referred to as "sub-capabilities." For example, a capability for plant operations would contain a set of major functional areas such as control room operations, field operations, operations support, etc. These are the sub-capabilities needed to comprise the scope of an operate capability. Within each sub-capability would be certain work processes consisting of standard work activities for achieving prescribed operational outcomes. These include work, risk, and reactivity management, etc. In the context of ION, these activities are designated as "work functions."

Therefore, sub-layering capabilities are the means by of breaking down capabilities to make the application of transformative concepts manageable. 


\subsubsection{Configuration of Capabilities}

"Configuration of capabilities" refers to the practical process of actually developing the capabilities. The output of this step is implementation of the capability within the new operating model - at least in its initial form. It is concerned with the minimum requirements in delivering the capabilities. It considers what existing resources can be used as building blocks for delivering the capabilities and identifies key requirements for developing the capabilities. Finally, it initiates a process for continuously maturing the capabilities so that they deliver predictable outcomes and are adaptable to changing busines conditions and opportunities.

\section{Xcel Energy's ION Application Experience}

In December 2018, Xcel Energy announced its industry-leading goal of achieving 100\% carbonfree power generation by 2050. This entailed a new nuclear business model to ensure that Xcel Energy's nuclear assets remain a cost-effective source of carbon-free energy well into the future. The new nuclear business model is a departure from nuclear industry norms and challenges traditional thinking and practices. The fundamentals of the new model are based on successful principles and techniques used in similar industries facing economic pressures. This model was built with the expectation of simultaneously maintaining high levels of performance and safety while achieving cost-competitiveness in the energy market.

\subsection{Xcel Energy's XE-1 Initiative}

Xcel Energy's NPPs are in a unique and challenging position in the domestic nuclear industry. The three reactors have some of the highest capability factors (>95\%) and lowest annual O\&M expenditures in the industry. However, when considering the combined three reactors with a maximum generating output (approximately $1600 \mathrm{MWe}$ ), the calculated operating costs ( $\$ / \mathrm{MWh}$ ) are non-competitive with other sources of electricity in the Upper Midwest. It is clear that, to remain in the Xcel energy portfolio, the Xcel Energy nuclear business needs to reduce its operating costs by one-third (33\%) over the next few years. In 2018, Xcel Energy partnered with Idaho National Laboratory and its LWRS Program. The objective of the partnership was to investigate new methods and models for lowering operating costs and site staffing levels closer to pre-Three Mile Island (TMI) levels. The business model chosen for evaluation was the IO model used in the Norwegian O\&G industry and their oil fields in the North Sea as shown in Figure 11.

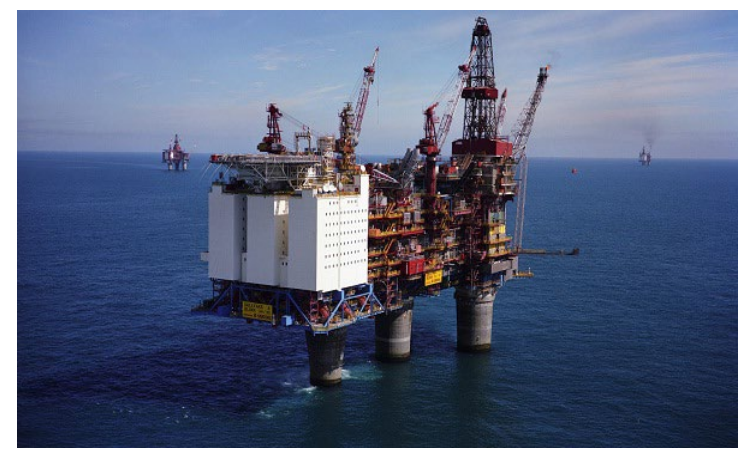

Figure 11. Offshore platform.

Applying IO principles to nuclear energy is a natural continuation of NEI Efficiency Bulletin 1723, "Transform the Plant Organization," which transformed nuclear operations into three main areas (i.e., Operate the Plant, Maintain the Plant, and Support the Plant). Simply stated, future nuclear organizations will operate the two nuclear plant sites like two oil platforms, with minimum staffing to operate and maintain the plant, led and supported by a central corporate organization. This central organization would leverage technology to streamline processes, utilize vender expertise, and provide needed resources for dealing with larger-scope or emergent issues.

Before detailing the new nuclear operating model, it is important to state the core requirements foundational to operate any nuclear facility-requirements that will have to be preserved. 


\section{a) Compliance Requirements}

The new nuclear business model is expected to be fully compliant with all applicable regulations, ensuring that the organization is always "inspection ready" and able to demonstrate compliance in daily operations. The organization will actively engage with industry groups and regulators using riskinformed and other advanced methodologies to achieve regulatory compliance or relax those regulations that provide little to no safety benefits, and will leverage new technologies and remote monitoring to meet previously manual-oriented regulatory requirements.

b) Performance Requirements

The organization will sustain high levels of performance based on specific thresholds of excellence. These thresholds will be set based on company expectations, industry stakeholder standards, and business model objectives. Efforts to be the best of the best are commendable but not always cost-effective after reaching what the industry recognizes as a high level of performance. Critical performance areas will be closely monitored for early indications of decline. Such indications will be promptly addressed to restore performance.

\section{c) Financial Requirements}

The cost of nuclear generation must remain competitive in the regional energy market. The market share for renewable energy is expected to continue to increase as the costs of renewable energy falls. It is a given that nuclear generation assets must drive down costs without sacrificing performance or safety. By maintaining focus on core O\&M competencies within an IO service model, higher levels of expertise can be obtained externally, and utilities can increase their operational focus and performance while reducing costs.

The new nuclear business model is best described through a diagram. The objective is to operate as one site with three reactors. Core business consists of areas in which we strive for high levels of proficiency in the "Operate" and "Maintain" groups. The "Support" group includes a mixed collection of in-house and external resources whose sole responsibility is to support core business ("Operate" and "Maintain") within a cost-sharing pooled resource structure. In addition to these three core business groups, a "Strategy group provides the long-term direction for the future of the business.

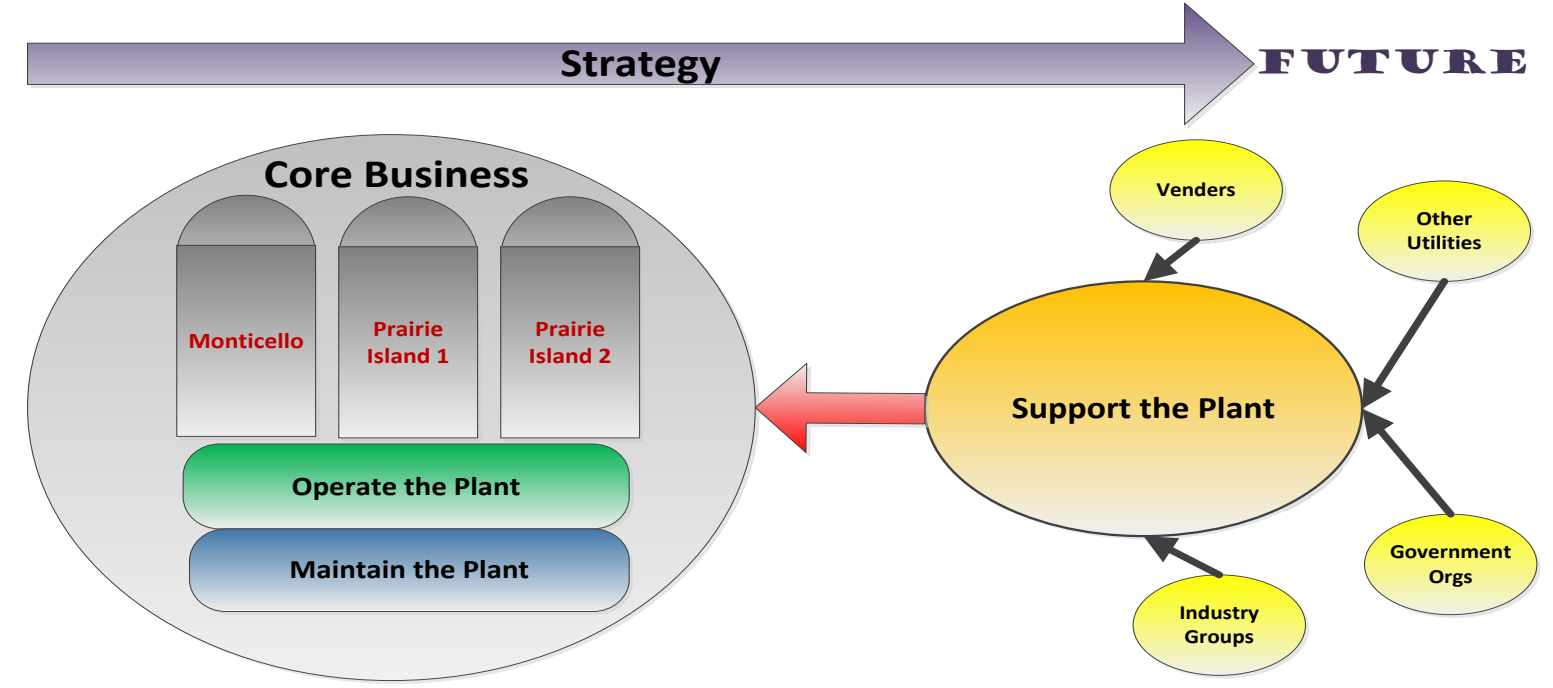

Figure 12. Grouping of nuclear operations.

Functions within each group:

- Operate the Plant - responsible for operating equipment to generate the product while the assets and people onsite. This group includes operations, chemistry, radiation protection, and security.

- Maintain the Plant - responsible for equipment performance to ensure predictable, reliable service from systems and components manipulated by the "Operate" group. The 
"Maintain" group includes electrical, mechanical, and instrument maintenance; the "fix it now" team; equipment reliability; plant modifications; work management; and outage management.

- Support the Plant - responsible for all support activities needed to operate and maintain the plant. This group includes engineering, training, emergency planning, regulatory affairs, performance improvement, and administrative functions.

- Strategy - responsible for setting the long-term direction of the organization and aligning key stakeholders to the vision. This group includes regulatory policy, strategic planning, strategic innovation, innovation projects, and fuel cycle planning.

Each group has its own unique mission and vison, core functions, and organizational structure. A vice president heads up each of the four groups. Under each vice president, a staff of managers, the directors, and general managers are arranged to provide leadership and oversight regarding their specific function(s).

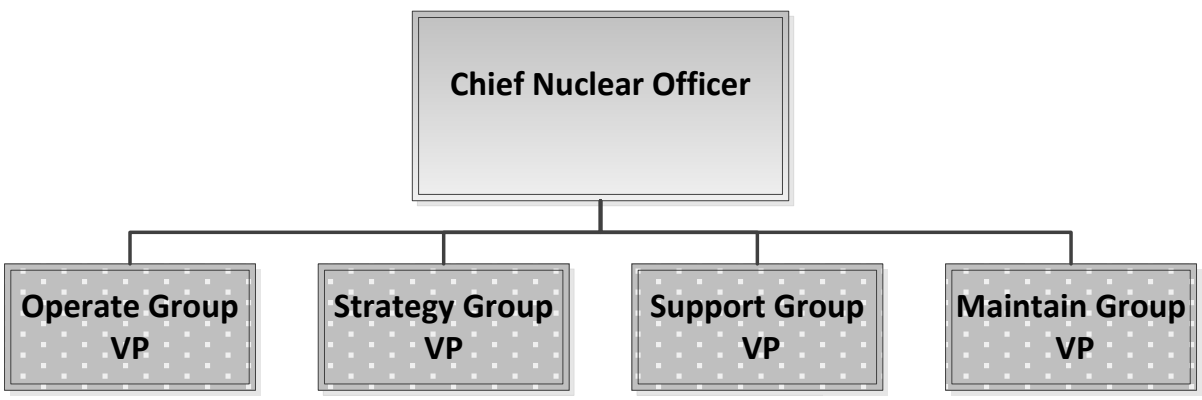

Figure 13. High-level organizational structure.

Important stakeholders in the new nuclear business model, the vendor partners have a shared interest in the success of the nuclear industry. A separate commercial model provides a basis for external business entities to establish strategic partnerships with Xcel Energy in executing the principles of the new nuclear business model. As a part of the transition, Xcel Energy will develop business partnerships with companies that can integrate with Xcel Energy's nuclear fleet to provide improved services at reduced cost. Identifying which services will be part of the "core business" and maintained in-house instead of being contracted out to a provider with specialized skills that mesh with Xcel Energy is a key part of this model.

Xcel Energy intends for its strong business relationships with these strategic partners to result in shared profitability, reduced costs, and improved performance throughout the nuclear fleet. The purpose of the commercial model is to outline this approach to all parties involved in this transformation.

\subsection{Integrated Operations for Nuclear}

The overall objective of this research collaboration is to deliver to the nuclear industry a validated means of bringing their operating costs in line with the realities of the electric market via transformation of the operating model. This will be accomplished through business-driven technology innovation. The two major barriers to extended plant life are addressed: technical and economic viability over the long-term.

The DOE LWRS Program - Plant Modernization Pathway focuses on developing a businessdriven approach to transforming the operating model for commercial NPPs from labor-centric to technology-centric - just as many other industrial sectors have done to survive in the marketplace. The specific objective is to derive a methodology and tool set from actual experience in collaborating with Xcel Energy for the following purposes:

- To transfer the ION methodology and tool set to industry

- To promote a transformed, sustainable NPP business model based on ION and businessdriven innovation 
- To leverage LWRS Program technology development to the fullest extent.

This ION framework is the aforementioned business-driven

- A market-based price point (typically the bus-bar cost in $\$ / \mathrm{MWh}$ ) for nuclear generation is established, then used to back out what the maximum total O\&M budget of the nuclear fleet should be to support this price. In turn, this budget is allocated across the nuclear organization in a top-down manner as the starting point of an iterative process. (Top-Down)

- Work functions are analyzed for aggressive opportunities to reduce workloads to only what is essential and can be resourced within this O\&M budget. (Bottom-Up)

- The streamlined work functions are then configured into a transformed operating model that leverages advanced technology and process innovations, resulting in a small onsite staff focused on daily operations, with all maintenance and support functions centralized or outsourced in on-demand service models.

\subsection{ION Process}

Through high-level discussions between the LWRS Program and Xcel Energy, it was recognized that there was an opportunity to collaborate in applying advanced technologies to the larger nuclear business model in order to improve performance and position NPPs for long-term economic success. In particular, within the LWRS Program Plant Modernization Pathway was a growing understanding that emerging technologies could do more than just address inefficiencies and obsolescence concerns over the present way NPPs are operated, but could in fact enable new work methods to produce better results at lower cost.

This resulted in a new way of thinking about applying technology in the field of nuclear power. When technology is used to improve performance and address obsolescence within the construct of how we currently operate the plants, we term it "modernization." On the other hand, when technology and innovation are used to enable a new, more efficient operating model, we term it "transformation." Transformation is what we see in other industrial sectors, where innovation enables a redefinition of how products are made and services are delivered.

The Plant Modernization Pathway's long-term research collaboration with IFE's Halden Reactor Project resulted in considerable awareness of the IO concept and how it successfully transformed the operating models for offshore O\&G production. The two respective teams worked with IFE to better understand how IO might address issues faced by U.S. nuclear power, particularly those aspects that closely parallel the issues facing the North Sea O\&G industry. It was decided that, with certain adaptations, the IO method was highly suitable for defining a better operating model for nuclear power.

The following sections describe how ION was initially applied within the XE-1 initiative to bring about the magnitude of transformation needed to meet Xcel Energy's future operational objectives. The information was largely taken from The Capability Approach to Integrated Operations Handbook [17].

\subsubsection{Setting Operational Context}

The operational context consists of all factors that must be addressed to be successful in the future environment of the company. They include such things as corporate vision and values, market opportunities and constraints, public safety, regulatory requirements, labor contracts, environmental considerations, employee well-being, public reputation, etc. Implementation of IO must address, or at least not conflict, with these factors.

\subsubsection{Operational context for nuclear plants}

Fortunately for the nuclear industry, these factors are very well-understood and incorporated into the operating culture. The U.S. nuclear industry is particularly known for its high-compliance culture, in addition to a safety culture unsurpassed in the history of industrial enterprises. Moreover, the industry is highly successful in achieving the intent of these operational context factors, due to the 
rigorous discipline and accountability it imposes on all its technical and business activities. Rare lapses in achieving these objectives are usually unintentional and quickly remedied.

The project with Xcel Energy involved confirmation of all of the operational context factors needing addressed in the project; these were in line with the ones mentioned above. The executive leadership was very clear that improvements to the business model and in reducing costs could not come at the expense of these other factors. So, the operational context factors were documented and recognized in team deliberations, with each improvement idea being tested as to whether it upholds them.

\subsubsection{Top-down budget allocation}

One special factor needing addressed was the cost of electricity from Xcel Energy's nuclear units. Xcel previously calculated what this cost would need to be to be competitive in the regional power market in the face of growing renewables and gas generation. And they made the decision not to rely on government-mandated rate subsidies that might change as the result of future political actions. From this cost of electricity, all components in the total cost could be derived, including the maximum allowable O\&M budget for the nuclear fleet. This was the top-down budget allocation process described earlier in this report.

\subsubsection{Identifying Capabilities}

A capabilities approach in IO is the structured development of key resources needed to realize the value of IO across organizational units, disciplines, and professions [10]. In this sense, they represent core functions essential to achieving the objectives of the enterprise. Some capabilities are specific to the nature of the business, while others represent more generic business functions common to all modern industries.

\subsubsection{Capability identification}

Within the Xcel Energy initiative, a number of working sessions were held to identify the needed capabilities. Examples from other industries were considered, particularly those developed by North Sea O\&G companies, due to its parallels with the nuclear industry. Also taken into consideration was the objective of reducing costs through work elimination, centralizing functions, and sharing expertise. Finally, consideration was given to positioning the company to expand business opportunities.

First, operational capabilities as described in Section 4.1 were grouped in a way that aligns closely with the intrinsic functions needed to conduct nuclear power generation. These groups were:

1. Operate the Plant

2. Maintain the Plant

3. Support the Plant

Obviously, these groups broadly cover the types of activities needed for long-term NPP operation. However, within these capabilities lies the flexibility to align organizations and deploy human resources in new, more efficient ways. They also enable new business models for sharing resources across multiple production units and geographical areas. For example, certain technical functions heretofore performed by dedicated resources onsite could be outsourced to expert companies able to perform them remotely on an as-needed basis. That means that the company would only pay for those resources on a part-time basis rather than carry them full time. Many other such efficiencies are enabled by the way these capabilities are defined.

A second grouping of support capabilities are the type broadly used across the enterprise to conduct work activities that fall within the operational capabilities. For Xcel Energy, the support capabilities are those needed to achieve the business objectives defined in the IO context. They are:
1. Adaptability
2. Analytics
3. Assurance
4. Collaboration 
5. Influence

6. Innovation

7. Risk-Informed

8. Workforce Development

These support capabilities have dual natures in that they are typically owned by a certain support organization but used extensively within other capabilities, both within the other support capabilities and within the operational capabilities. In this sense, the support capabilities are cross-linked to each other and to the operational capabilities where they are needed.

Regarding the scope of the support capabilities, the intent is that they are broadly defined to meet the needs of the entire organization rather than having multiple, customized instances of the same capabilities for each sub-organization. There is also expected to be a great degree of standardization in how the capabilities are defined, providing economy in developing and maintaining them.

A third grouping of foundational capabilities represents the enterprise's hard production assets, such as the physical plant. Obviously, these capabilities are the frontline basis of production. They are capabilities in the sense that they can produce the tangible products of the enterprise as long as they are successfully operated and maintained within the economic constraints. They are:

1. Physical Plant

2. Plant Information Data Stream

3. Plant By-Products

For the most part, these foundational capabilities are already developed, but relationships to both the operational and support capabilities must be well-defined. For instance, it is the systems, structures, and components of the physical plant that are the principal objects of the "Operate the Plant" and "Maintain the Plant" groups. The "Operational" and "Support" groups, which depend on plant sensor information and other such data, relate to the Plant Information Data Stream capability.

The Plant By-Products capability is somewhat unique in that it represents commercial opportunities for the enterprise other than power generation. A good example is potentially using plant heat and electricity to conduct electrolysis of water for hydrogen generation. Hydrogen, in turn, is a highly marketable commodity used in a number of industrial processes. Use of plant energy for hydrogen production could complement power production when the price of electricity is low. It is readily evident that the Plant By-Products capability would need to be connected to all other capabilities in both the "Operational" and "Support" groupings.

\subsubsection{Capability stack model}

The next step is the development of a capability stack model, an abstraction used to manage the complex interrelationships among the various capabilities. The complexity arises because the capabilities, by definition, are scalable and reusable; therefore, they are connected to all other capabilities and the underlying work functions in need of them. Thus, the capability stack model is defined as:

.... a layered representation of a complex system. The stack model seeks to decouple the complexity of the system by introducing distinct layered activities connected by standard interfaces. [18]

The layers of the stack model are based on the assumption that the capabilities of a lower level are needed to execute the capabilities of a higher level. It is further assumed that information can be exchanged across the layers via standard interfaces. The following are characteristics that describe the layers:

1. Each layer must have a dominant or compelling value proposition.

2. Each layer must have clearly defined and shared interfaces with adjacent layers.

3. Each layer must reflect an active market for products or services. 
4. Each layer much have a well-defined business-oriented set of metrics that reflect the core value proposition.

The capability stack model depicted in Figure 14 was developed by Xcel Energy to represent their defined capabilities for nuclear power generation.

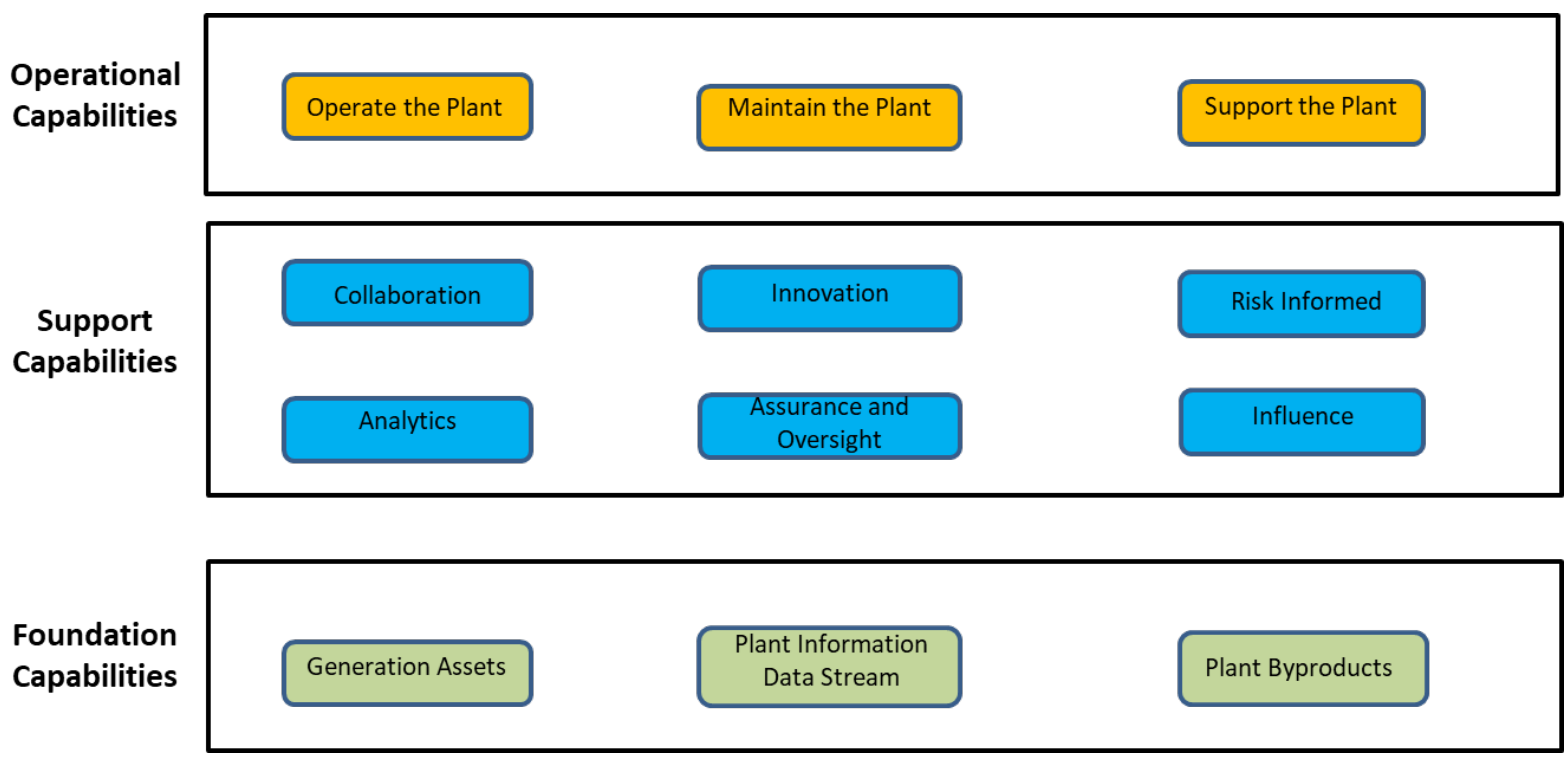

Figure 14. Xcel Energy's capability stack model.

\subsubsection{Sub-layering of Capabilities}

The next step in the process is the sub-layering of the capabilities. This consists of breaking down the capabilities into functions needed across the organization. These sub-layers are referred to as "subcapabilities"-within which, individual work functions are identified.

\subsubsection{Capability teams}

Xcel Energy defined capability teams for each of the three operational layer groups: Operate the Plant, Maintain the Plant, and Support the Plant. These teams were comprised of organizational leaders and subject matter experts to ensure that the capabilities were suitable for addressing future work needs and delivering sufficient cost savings.

An orientation session was held with each team, consisting of background material on the company situation and objectives, background on the IO experience in the North Sea, the process of defining capabilities, and, finally, the deliverables resulting from the process.

The teams were instructed to develop a vision of the future that reflects how work functions could be achieved more effectively through technology innovation. They were facilitated by XE-1 team members to ensure that the vision and products were in keeping with the expectations of the broader effort.

The XE1 team served as the capability team for the support and foundational layers of the capability stack, in that these capabilities span all organizations and require special insight into those technologies that enable future ways of working. In particular, the support capabilities had to be broadly defined to serve all the sub-capabilities and associated work functions in the operational layer. For example, the Collaboration capability will provide functionality to virtually every work function in the operational layer, ranging from virtual meetings to on-location support of field work activities by remote expert parties.

\subsubsection{Defining elements of capabilities - PTPG}

The capability teams were tasked with identifying the process, technology, people, and governance (PTPG) elements of the sub-capabilities, based on the new work methods envisioned. 
These were captured in a large tabular document describing the impact on each element and how the elements interrelate to achieve transformative ideas.

It was also noted that certain elements will depend on other capabilities and sub-capabilities, so these relationships were also noted. These relationships help define the total functionality of the subcapabilities when considering how they are expected to contribute to other sub-capabilities. Again, using Collaboration as an example, when an Operate the Plant sub-capability was defined as relying on a remote party to conduct an activity, it was simply noted that this would be provided by the Collaboration capability. So, this informed the Collaboration capability definition with respect to its role in serving other capabilities.

In many cases, defining the PTPG elements was difficult except in the context of specific work functions. In other words, the work functions drove different needs in the PTPG elements, based on the technical activities within a work function. This is described in the next section.

\subsubsection{Identifying work processes}

Xcel Energy had existing documentation of their work processes across all nuclear organizations. These were used, when needed, to define work functions under the sub-capabilities. As stated in Section 4.3.3.2, it became necessary in some cases to define PTPG elements in the context of a specific work function to get the right level of specificity for the needs. In turn, the aggregate of these work-function-level PTPG elements were rolled up to comprise the ones at the sub-capability level.

A second reason for identifying work functions is to utilize enablers of cost savings in the form of work-reduction opportunities. This is critical to the overall top-down methodology for reducing the workload to something supportable by the market-based price of power generation. Work-reduction opportunities can only be applied at the work-function-level, as described in the next section.

\subsubsection{Identification of work enablers and work reduction opportunities}

A process for determining the cost reduction that can be credited to work functions was developed and joined to the capability-development process. The combined processes are shown in Figure 15.

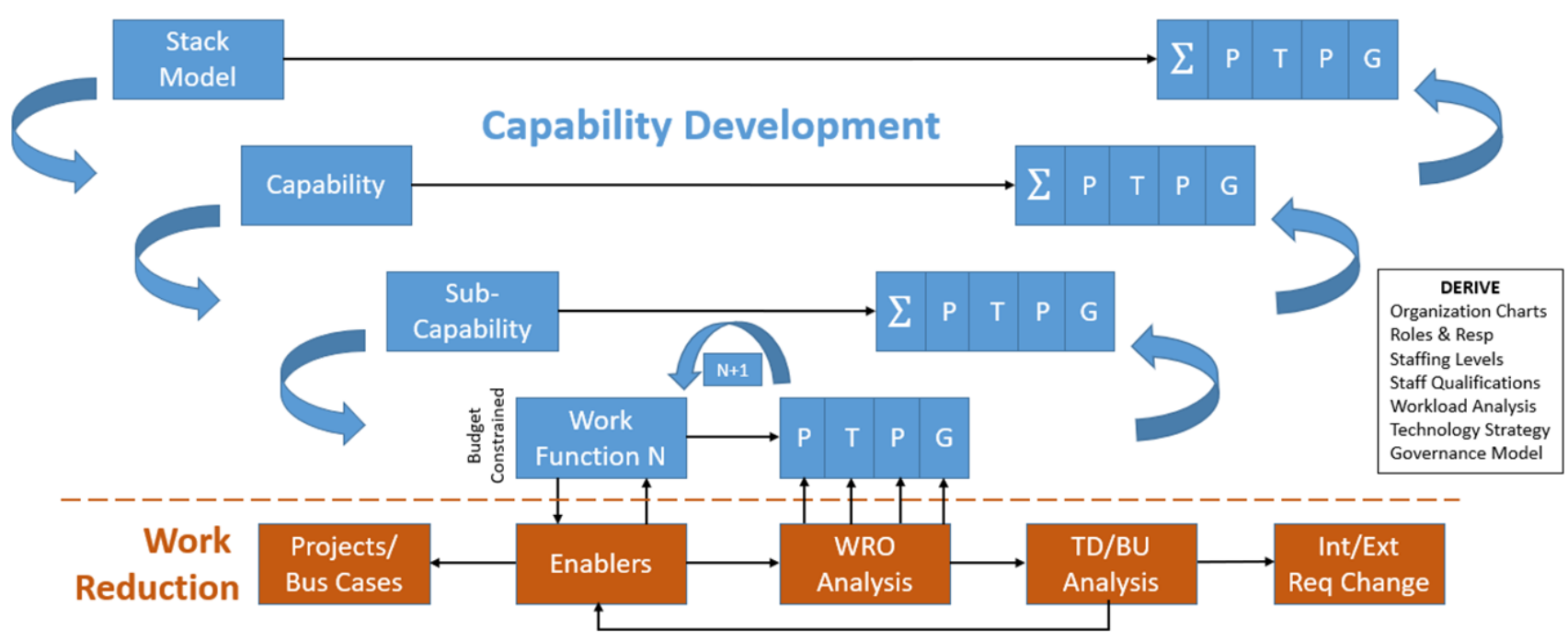

Figure 15. Combined IO and work-reduction processes.

Once the work function candidates for work reduction were defined, cost-efficiency enablers for these work functions were identified by each organization in Xcel Energy. This consisted of a general description of how cost savings could be achieved and what was needed to accomplish this. In turn, an ongoing process was initiated to analyze these enablers. This entails categorizing the cost savings in 
terms of the type of cost savings such as requirement changes, process improvements, technology application, or outsourcing.

Once fully developed, work reductions were analyzed in terms of their effects on the PTPG for the associated work function. This led to revising the PTPG for the work function, based on how it will work in the future. Then, the new PTPG requirements were rolled up into the synthesis of the higher-level PTPG analysis through the sub-capability, capability, and ultimately the entire capability stack model. This high-level PTPG formulation became the basis of the transformed operating model.

Continuing the work-reduction analysis, the process provides for conducting the topdown/bottom-up analysis to ensure that sufficient work reductions were achieved for the marketbased budget allocations to be met throughout the organization. It provides for identifying the internal/external requirement changes needed to enable certain work reductions. Finally, it provides the basis for formulating development projects and business cases, including the aggregating of similar technology applications or process changes that provide similar benefits across the organization.

\subsubsection{Configuration of Capabilities}

The final step in the IO process is the configuration of capabilities, though this is the most intensive part of the process. It consists of the upward synthesis of the PTPG analysis, as introduced in Section 4.3.3. Development of this process is underway at the time of this report and is described further in Section 4.5.1.

\subsubsection{ION-Derived Implementation Documents}

The following sections describe the key implementation documents traditionally used in organization design and implementation and can be derived from the ION process.

These documents become part of the "governance" element of the PTPG analysis, among other key types of documents such as directives and procedures.

\subsubsection{Organization charts}

While capability development does not directly define the organization, it logically groups work functions according to how they were transformed by the IO method. This gives rise to the development of the optimum organizational structure for executing the capabilities. In the case of Xcel Energy, this organizational structure was anticipated early in the process and became the basis for certain organizational structures and combinations, including the allocation of market-based budgets in a step-down manner over a certain number of years. However, as the practical effects of the transformed business model become more apparent, the organizational structure will continue to be assessed and adjusted as needed.

\subsubsection{Roles \& responsibilities}

Roles and responsibilities for both organizational units and employee types are principally derived from the "process" and "people" elements of the PTPG analysis. It is expected that they will change considerably as the work functions are transformed by IO concepts. For example, new, more automated technologies might enable generally trained workers to perform tasks heretofore requiring a highly trained expert. This same automation might create enough work efficiencies to enable a multi-skilled worker to conduct work activities formerly accomplished by multiple workers. It is in this way that roles and responsibilities for organizations and workers will be modified.

\subsubsection{Staffing levels}

Staffing levels are set by the amount of residual work in various work functions, following application of the efficiency enablers. Some work functions will be unchanged by the capability analysis and thus remain what they were before the application of IO. However, most will be changed in some way, thereby contributing to the requisite cost reductions needed to achieve the market-based budget. 
A key factor in staffing levels will be whether the work functions are needed on a full-time basis, can be shared among multiple NPPs, or could potentially be outsourced. A key principal of ION is to maintain a lean staff at NPPs to address the baseload work, with all additional support ideally being provided on an as-needed basis rather than through full-time staffing.

\subsubsection{Staff qualifications}

Staff qualification changes will be identified through the "people" element of the PTPG analysis, reflecting the role of staff in regard to the transformed work functions. This will closely align with the new roles and responsibilities described above. For instance, certain types of material condition surveillance are conducted these days by field technicians using portable test equipment that must be set up in the field to collect data. In the future, this surveillance data might be collected by permanent sensors mounted in these field locations, and the new task will be to analyze the data sent back from these sensors. Therefore, staff qualifications for the same work function could be considerably different.

These new staff qualifications must be aggregated and analyzed to determine what training programs are needed to ensure staff competence. In general, it is expected that digital automation technologies will be exploited to make using these technologies as simple and intuitive as possible, reducing reliance on initial and refresher worker training for proficiently conducting the work functions.

\subsubsection{Workload analysis}

Workload analysis is similar to staffing level determination but must also consider timing with respect to peak work periods. As with the staffing level, it is primarily derived from the "people" element of the PTPG analysis. In nuclear generation, there are certain drivers in work scheduling for such factors as urgency due to generation threat or regulatory requirements, as well as other factors such as conducting the work during a refueling outage or optimum work window. Therefore, staffing levels, whether baseload or augmented resources, must be sufficient to meet peak workloads that cannot otherwise be better levelized.

\subsubsection{Technology strategy}

A technology strategy document is needed to plan the orderly implementation of technology applications used to transform work functions. One important aspect of this is a technology readiness assessment to determine which technologies are ready for near-term implementation and how they will evolve over time to provide even greater functionality. Another aspect is technology integration, specifically in regard to understanding the interrelationships among technologies and how they work together to enable a broader work function transformation. Some technologies are "enabling," meaning they do not provide bottom-line value by themselves but enable other technologies to work more effectively. A good example is wireless communications, which is useless by itself but can allow for smart work packages in the field to retrieve information determined necessary during a job activity.

A technology strategy is also used to aggregate the business cases for similar work function efficiencies across the operating model in order to thereby determine the total value the technologies offer the organization and what the total return on investment will be. Finally, it is used to develop a technology deployment plan that considers all aspects of change management and support functions needed to introduce the technologies into the work functions.

\subsubsection{Governance model}

The governance model is the totality of the management controls for conducting business operations for the nuclear fleet. It addresses all desired business practices, internal and external constraints, and the application of the organization's values and operating principles. These management controls extend from high-level policy statements down to specific work-process instructions. They include such things as employee policies and procedures, quality assurance programs, administrative procedures, technical procedures, operating manuals, information technology policies, etc. 
Changes to the existing governance model are identified through the "governance" element of the PTPG analysis. As part of capability development, the existing governance documents must be evaluated to determine how they are affected by the formulation of the capabilities. Revision of these affected documents must be part of the change management process for transitioning to the ION model. Revisions affecting management policies must, of course, be reviewed for acceptability by the senior leadership of the organization.

\subsection{ION Analysis Tools}

This is the collection of computer-based applications developed and used in the framework processes, They will be provided as deliverables to the industry for utilities desiring to conduct ION analysis in the same manner as the collaboration with Xcel.

\subsubsection{Integrated Operations Capability Analysis Platform (ICAP)}

This is a repository of the information required to analyze NPP work functions and apply innovative concepts to them. The information includes descriptions of the work functions, any constraints on the work functions (regulatory, policy, etc.), descriptions of work-reduction opportunities regarding individual work functions, quantification of labor and non-labor savings achieved through those opportunities, and certain risk-assessment information in pursuing those opportunities.

\subsubsection{Innovation Portal (IP)}

This is a repository for a wide range of information on innovative technologies applicable to NPPs. This database will be seamlessly joined to the Work Function Analysis Database so the information can be accessed and applied during work function analysis. It will also be accessible in standalone form as a web app so nuclear utilities can retrieve the information directly.

\subsubsection{EPRI Business Case Analysis Method (BCAM) Interface}

EPRI Business Case Analysis Method (BCAM) Interface - The Electric Power Research Institute (EPRI) has developed a comprehensive business case application based on a prior LWRS projectdeveloped a business-case tool known as the Business Case Methodology Workbook (BCMW) - a complex Excel workbook that compiles the detailed work-activity savings from NPP innovation and aggregates the benefits into an overall business-case format, providing a calculation of harvestable savings (reduced FTE) and the present worth of the benefits. The ICAP will be interfaced, with minor adaptations, to the BCAM so labor and non-labor data can be seamlessly transferred to produce the needed investment business cases.

\subsection{Future ION Activities}

\subsubsection{Configuration of Capabilities - FY 2021}

As introduced in Section 4.3.4, the major project activity of FY 2021 will be to develop a graded method for the configuration of capabilities, meaning a detailed analysis of the PTPG elements of the capabilities to generate requirement specifications for technologies, innovations, and other changes that transform how work is performed in the future operating model. This method will be informed by the substantial experience of DOE national laboratories in engineering practices and human factors science in order to ensure that socio-technical considerations are addressed. It will draw on successful experiences in complex human-technical integration, not only from the North Sea experience with IO but also from similar undertakings by the U.S. Navy in designing advanced combat vessels with highly integrated technology. It will be graded in the sense that certain development and validation activities will be applied in a manner commensurate with the complexity and criticality of a given capability.

This method will be developed and applied to three capabilities or sub-capabilities of varied complexity from a technology and human interface standpoint. The method will be refined through lessons learned in the development work. 


\subsubsection{Virtual Organization - FY 2022}

Section 3.1.2 introduced the notion of generations of IO development, and that Generation 2 involved the expansion of IO to third-parties supporting the organization. The focus of the project work in FY 2022 will be the further development of the Collaboration capability to enable future business models in which parties are seamlessly integrated into real-time work activities from remote locations. Generation $2 \mathrm{IO}$ is key to further performance improvement and cost reduction by enabling utilities to outsource critical skills and expertise not needed on a full-time basis and not central to the core mission of reactor and power operations. However, these services are required to be just as effective as if they were onsite and being provided by the plant staff. The Collaboration capability must provide all information access needed to achieve appropriate situational awareness by the remote resources. It must provide a means to interact with the work activities in a real-time fashion. As such, this Collaboration capability will foster a virtual organization of equal or greater effectiveness compared to the current large staffs at NPPs - and at substantially reduced costs.

\subsubsection{Technology Integration - FY 2023}

As described in Section 4.3.5.6, technology integration is a key component of successful IO implementation. The project work in FY 2023 will focus DOE resources on addressing how NPP technologies are evolving to greater functionality and be integrated for synergistic benefits in performance and cost management. Many technologies introduced into nuclear work practices are implemented in the form of how these functions were conducted in the past. For example, computerbased procedures can be highly automated but still be similar in form to paper-based procedures. Technology integration will introduce new combinations of technologies to achieve the same desired outcomes as the predecessor activities but in more efficient ways. This will create a more futureoriented roadmap for technology integration based on optimum timing and order of implementation.

\section{ION Key Performance Indicators}

KPIs are essential for any business to understand whether its goals and objectives are being achieved. In the case of IO, there are two separate sets of outcomes to measure: (1) fundamental business objectives and (2) IO implementation or transition to the new business model. Within these categories are both performance and diagnostic measures, the latter being how well processes are working and - in particular - whether new IO concepts have been fully exploited. These diagnostic measures do not represent external value.

As the operating model transforms to adopt IO principles, it is critical to establish metrics and KPIs to measure the performance of processes and systems, track the progress of the transition to the IO model, provide trending information for continuous improvement, and increase accountabilities and process ownership. Similarities with the O\&G, airline, and manufacturing industries, as outlined in Section 3.1.3, also lend themselves to applying similar KPIs. This results in a set of new or modified KPIs.

Using a tiered hierarchy of KPIs with varying levels of granularity and different audiences/owners is a best practice, as depicted in Figure 16. For instance, top-level (i.e., Tier 1) KPIs would capture long-term performance across the fleet and indicate the overall health of the individual nuclear plants and nuclear fleet. Progressing to lower tiers, the KPIs become more plant-, department-, or systemspecific and would be reported more frequently to lower levels of the organization. 


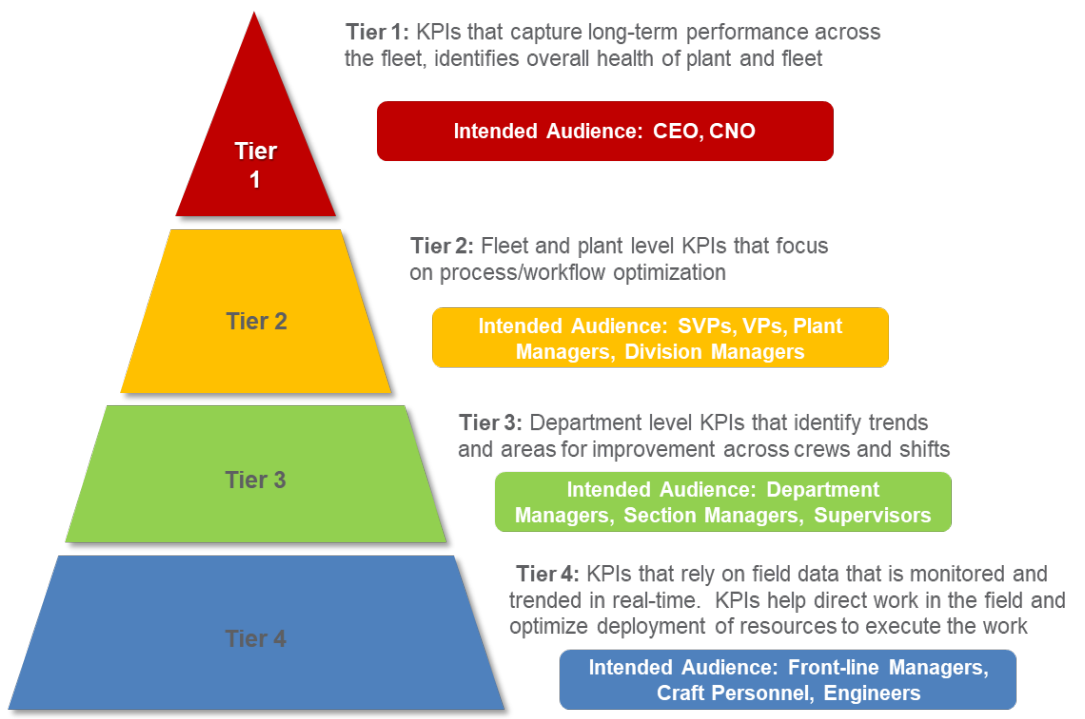

Figure 16. Tiered hierarchy of KPIs.

Further, these KPIs should adhere to agreed-upon design principles, which may include:

- Clear ownership

- Clear definitions (i.e., what the KPI means and what it measures)

- Measuring success with line of sight through the organization; ensuring that the entire organization is focused on the right goals

- Easy to calculate and easy to track; not manual

- Cannot be manipulated

- Reinforces capability thinking

- Influences future sustainability (i.e., long-term technical and economic viability)

- Drives/shapes desired behavior

- Clear as to which roles or functions are responsible, and why

- Clear as to what activities drive it

- Understanding of why the KPI is used (e.g., diagnostic or "real" indicator of performance)

- Understanding of why the KPI exists (e.g., regulatory-driven)

- Raw number or calculation vs. index

Additionally, KPIs that track progress made in transitioning to IO principles, which are leading indicators, and those that incorporate some form of "crowd-sourcing" are preferred.

To revamp KPIs to measure the performance of the new operating model, the above design criteria is applied, integrating lessons learned from the $\mathrm{O} \& \mathrm{G}$, airline, manufacturing, and other capital-intensive industries. The resulting KPIs measure performance for each of the three primary capabilities. KPIs developed specifically to measure the performance of the new IO model are emphasized in bold. In general, these new KPIs measure the efficiency and effectiveness of the IO model in maximizing the reliability and availability of the plant while simultaneously minimizing costs. For instance, the forced loss rate KPI measures the percentage of energy generation that a plant is incapable of supplying to the grid as a result of unplanned losses (e.g., unplanned shutdown or load reduction), while the MWh per person-hour onsite KPI measures the total MWh divided by the person-hours for all site personnel (employees and contractors). Continuous monitoring of these KPIs is essential for maintaining performance while correctly resizing the business model and realigning plant resources. 
Table 1. Tiered KPI chart.

Tier $1 \mathrm{KPIs}$ - Overall Performance across the Fleet

- Unit Capability Factor - NRC Regulatory

- Total O\&M Costs

- Total Capital Costs Performance

- INPO Plant

Performance Index
- Industrial Safety (DART) Performance

- Forced Loss Rate (FLR)

- MWh per Person-Hour Onsite

Lower Tier Metrics - Aligned to Capabilities

\begin{tabular}{|c|c|c|}
\hline Operate the Plant & Maintain the Plant & Support the Plant \\
\hline $\begin{array}{l}\text { PPI sub-model index- } \\
\text { Operations, } \\
\text { Operational Focus } \\
\text { - } \text { Department Clock } \\
\text { Resets } \\
\text { - } \text { Limiting Condition of } \\
\text { Operation (LCO) Events } \\
\text { - Operational Transient } \\
\text { Events } \\
\text { - Clearance and Tagging } \\
\text { Events } \\
\text { - Operational Decision- } \\
\text { Making Events } \\
\text { Crew Clock Resets } \\
\text { - Operational } \\
\text { Fundamental Errors } \\
\text { - Rad Control Events } \\
\text { - Reactivity Management } \\
\text { Unscheduled } \\
\text { Equipment-Related } \\
\text { Downtime } \\
\text { Current Employee } \\
\text { Assessment of Plant } \\
\text { Condition } \\
\text { Contractor Count } \\
\text { Weekly Overtime \% }\end{array}$ & $\begin{array}{ll}\text { - } & \text { EQP } \\
\text { - } & \text { PPI sub-model index- } \\
\text { Equipment Reliability } \\
\text { - } \text { Maintain the Plant } \\
\text { Capital and O\&M } \\
\text { - Integrated Plant } \\
\text { Function Material } \\
\text { Condition } \\
\text { - Unplanned } \\
\text { Maintenance Checks } \\
\text { and Events } \\
\text { - Maintenance Cost for } \\
\text { MWh Generated } \\
\text { - Rework Percentage } \\
\text { - Maintenance } \\
\text { Productive Time } \\
\text { - Preventive and } \\
\text { Predictive } \\
\text { Maintenance Ratio } \\
\text { - Critical Corrective } \\
\text { Maintenance Items } \\
\text { - Work Orders Ready to } \\
\text { Work } \\
\text { \% of Mabor Planning Quality } \\
\text { Crews that are Multi- } \\
\text { Disciplined } \\
\text { - }\end{array}$ & $\begin{array}{l}\text { - PPI sub-model index- } \\
\text { Management } \\
\text { Challenges } \\
\text { - Trend in NRC violates } \\
\text { and X-cuts } \\
\text { - Accreditation Health } \\
\text { - } \quad \text { Drill and Exercise } \\
\text { Performance }\end{array}$ \\
\hline
\end{tabular}

Bold text denotes new KPIs developed to measure the performance of the IO model. 


\section{Conclusions}

For nuclear power to survive as a competitive energy source, major structural changes must be undertaken to dramatically reduce O\&M costs while still achieving excellent availability and a high degree of safety. With many electric utilities announcing plans to achieve low- or zero-carbon generation by the middle of this century, nuclear-generated electricity as a reliable, non-emitting resource can be part of achieving this goal. As stated in a 2018 MIT report, "Premature closures of existing plants undermine efforts to reduce carbon dioxide and other power sector emissions and increase the cost of achieving emission reduction targets" (2). In many cases, when an NPP is shut down prematurely, generation is replaced not by another non-emitting source but by natural gas, leading to increased emissions.

Nuclear power had its best year ever in 2019, as reported by NEI and the Electric Utility Cost Group [19]:

- Highest generation ever

- Supplied almost $55 \%$ of carbon-free electricity in the nation

- Avoided over 476 metric tons of $\mathrm{CO} 2$

- Fleet average capacity factor: $93.4 \%$

- Average generating cost: $\$ 30.42 / \mathrm{MwHr}$

While this is a significant accomplishment, it probably represents the best that can be done operating under the existing paradigm. NEI's "Delivering the Nuclear Promise" implemented some overdue process changes, but they were mostly limited to "low hanging fruit" and did not involve equipment modernization or any significant addition of new technology. In addition, virtually all the existing fleet long ago "paid of its mortgage," so the current average generating cost does not include any costs involving the original construction.

Nuclear power has reached - and probably passed - the "strategic inflection point" and is nearing the point at which it will be impossible to recover unless drastic measures are taken. Ten NPPs shut down primarily due to economic pressure over the last seven years, and five more have plans to shut down over the next five years. In addition, 15 plants were saved from economic shutdown due to temporary state economic relief (3). If nuclear power is to be preserved for future generations, a significant transformation must take place.

IO, as developed and implemented by the North Sea O\&G industry, transformed their business and enabled them to achieve competitiveness despite increased labor costs and dropping revenue. This transformation was performed while still achieving high levels of safety. Given that offshore drilling and production facilities are very similar to nuclear facilities in terms of complexity, safety, and environmental impact, IO should be investigated as a possible model for transforming the nuclear industry.

Traditional approaches to business transformation that essentially focus solely on either technology innovation or process changes are destined to fail. The strength of the IO transformation model is that it requires integration of the transformation process across the four primary dimensions of any business endeavor: process, technology, people, and governance. In addition, advanced communication and analysis technologies enable most work to be done in an optimum fashion, independent of physical location.

Capability thinking is another powerful tool in the arsenal of transformation. It can be used to design the new organization so it can provide the necessary skills, abilities, and resources to perform work in a new, effective way. A focus on capability assessment will also break down "stove pipe" structures and harmonize the provision of necessary resources at the right time and in the right place.

In summary, IO with capability thinking shows promise as a model to guide the nuclear power industry in transforming to meet current and future challenges posed by the new economic realities of power generation. It is clear that following the current course of limited technical upgrades and evolutionary process changes will not sufficiently guarantee the survival of most of the U.S. nuclear fleet. 


\section{Next Steps}

To fully evaluate IO and capability thinking to determine their applicability to the nuclear power industry, the following near-term actions are planned as described in Section 4.5.

1. Develop an industry-transferable process for significant nuclear work function innovation based on Integrated Operations concepts.

2. Develop a methodology tool set for nuclear work function innovation based on macro ergonomics systems approaches and solutions.

3. Develop advanced concepts in digital remote collaboration to enable virtual organizations to conduct nuclear plant work functions seamlessly with the on-site staff.

4. Develop a technology integration roadmap that maximizes nuclear plant performance improvement and cost reduction in plant control and monitoring, work activity automation, worker efficiency, human performance, risk management, and operational decision making, through the synergistic combination of advanced digital technologies.

\section{References}

1. Idaho National Laboratory Light Water Reactor Sustainability Program website, https://lwrs.inl.gov/SitePages/Home.aspx, Retrieved 2020-07-19.

2. Department of Energy, Office of Nuclear Energy, Light Water Reactor Sustainability Program Integrated Program Plan, INL/EXT-11-23452 Revision 7, Idaho National Laboratory, November 2018.

3. Lybeck, N., Thomas, K., Plant Modernization Technical Program Plan, INL/EXT-13-28055 Revision 8, Idaho National Laboratory, September 2018.

4. Xcel Energy, Form 10-Q, Quarterly Report, Filing Date Apr 27, 2018. secdatabase.com. Retrieved May 5, 2018.

5. Roberts, David (2018-12-05). "For the first time, a major US utility has committed to $100 \%$ clean energy." Vox. Retrieved 2018-12-07.

6. Dominion News Release, Dominion to Close/Decommission Kewaunee Power Station, October 22, 2012.

7. Buongiorno, J., Corradini, M., Parsons, D., Petti, D., The Future of Nuclear Energy in a Carbon-Constrained World, Revision 1, Massachusetts Institute of Technology, 2018

8. U.S. Energy Information Agency, Levelized Cost and Levelized Avoided Cost of New Generation Resources in the Annual Energy Outlook 2019, February 2019.

9. Thomas, K., and B. Hallbert, 2012, Long-Term Instrumentation, Information, and Control Systems (II\&C) Modernization Future Vision and Strategy, INL/EXT-11-24154, February 2012

10. Institute of Nuclear Power Operations, Industry Cumulative Impact Summary Report, October 2013.

11. Nuclear Energy Institute, Delivering the Nuclear Promise: Advancing Safety, Reliability and Economic Performance, February 2016.

12. SPE-170630-MS Intelligent Energy: A Strategic Inflection Point Mark Lochmann, OVS Group; Ian Brown, Platts, Society of Petroleum Engineers, 2014.

13. Grove, Andrew S., Only the Paranoid Survive: How to Exploit the Crisis Points That Challenge Every Company, Crown Publishing, 1996.

14. U.S, Department of Energy, Office of Energy Efficiency and Renewable Energy, 2018 Wind Technologies Market Report, 2018. 
15. Boardman, R., Suk Kim, J., Hancock. S., Hu. H., Frick, K., Wendt, D., Rabiti, C., BraggSitton, S. Elgowainy, A., Weber, R., Holladay, J., Evaluation of Non-electric Market Options for a Light-Water Reactor in the Midwest, Idaho National Laboratory, 2019.

16. Drøivoldsmo, A., Rindahl, G., McDonald, R., Lessons Learned from Integrated Operations in the Petroleum Industry, Institute for Energy Technology. 2019.

17. Reegård, K., Drøivoldsmo, A., Rindahl, G. and Fernandes, A. The Capability Approach to Integrated Operations Handbook, Center for Integrated Operations in the Petroleum Industry, Trondheim, Norway 2014.

18. Henderson, J., Hepso, V., Mydland, O., What is a Capability Platform Approach to Integrated Operations? An Introduction to Key Concepts, Business Science Reference, 2013.

19. Nuclear Energy Institute, Nuclear by the Numbers, April 2020. 


\section{Appendix A}

Lessons Learned from Integrated Operations in the Petroleum Industry 
